\title{
The Transcription Factor FgStuAp Influences Spore Development, Pathogenicity, and Secondary Metabolism in Fusarium graminearum
}

\author{
Erik Lysøe, ${ }^{1}$ Matias Pasquali,, ${ }^{2,3}$ Andrew Breakspear, ${ }^{2}$ and H. Corby Kistler, ${ }^{2,4}$ \\ ${ }^{1}$ Department of Plant Health and Plant Protection, Bioforsk-Norwegian Institute of Agricultural and Environmental Research, \\ 1432 Ås, Norway; ${ }^{2}$ Department of Plant Pathology, University of Minnesota, St. Paul 55108, U.S.A.; ${ }^{3}$ Centre de Recherché \\ Public, Département Environment et Agro-biotechnologies, Gabriel Lippmann, L-4422 Belvaux, Luxembourg ${ }^{4}$ United States \\ Department of Agriculture-Agricultural Research Service Cereal Disease Laboratory, St. Paul, MN 55108, U.S.A.
}

Submitted 25 March 2010. Accepted 21 September 2010.

Fusarium graminearum is an important plant-pathogenic fungus and the major cause of cereal head blight. Here, we report the functional analysis of $\mathrm{FgStuA}$, the gene for a transcription factor with homology to key developmental regulators in fungi. The deletion mutant was greatly reduced in pathogenicity on wheat heads and in production of secondary metabolites. Spore production was significantly impaired in $\Delta F g S t u A$, which did not develop perithecia and sexual ascospores, and lacked conidiophores and phialides, leading to delayed production of aberrant macroconidia. FgStuAp appears to act as a global regulator that may affect many diverse aspects of the life cycle of $\boldsymbol{F}$. graminearum. Transcriptome analysis shows that thousands of genes are differentially expressed in the mutant during asexual sporulation and infection of wheat heads and under conditions that induce secondary metabolites, including many that could account for the mutant phenotypes observed. The primary regulatory targets of FgStuAp are likely genes involved in cell-cycle control, and the predicted FgStuAp sequence has an APSES domain, with homology to helixloop-helix proteins involved in cell-cycle regulation. The $\mathrm{As}$ pergillus StuAp response element (A/TCGCGT/ANA/C) was found highly enriched in the promoter sequences of cellcycle genes, which was upregulated in the $\triangle F g S t u A$ deletion mutant.

The APSES proteins are a conserved class of transcription factors that are unique to fungi, and are known to regulate key developmental processes in ascomycetes. These transcription factors are often involved in developmental programs, such as sexual maturation in Neurospora crassa (Asm1p), conidiophore morphogenesis with formation of metulae and phialides in Aspergillus nidulans (StuAp), dimorphic switching and chlamydospore formation in Candida albicans (Efg1p), and pseudohyphal growth in Saccharomyces cerevisiae (Phd1p and Sok2p) (Ramirez-Zavala and Dominguez 2008). The original members (Asm1p, Sok2p, Phd1p, Efg1p, and StuAp) were

E. Lysøe and M. Pasquali contributed equally to this work.

Corresponding author: E. Lysøe; Telephone: +47 92609123; Fax: +47 64946110; E-mail: erik.lysoe@bioforsk.no

* The $\boldsymbol{e}$-Xtra logo stands for "electronic extra" and indicates that five supplementary tables and three supplementary figures are published online. used to designate the group, and they behave as developmental regulators in their respective fungal species (Aramayo et al. 1996; Gimeno and Fink 1994; Miller et al. 1992; Stoldt et al. 1997; Ward et al. 1995). Developmental regulators can be part of many cellular processes, and the APSES transcription factors have been connected to expression of genes involved in metabolism (Doedt et al. 2004), secreted enzymes (Korting et al. 2003), cell wall (Sohn et al. 2003), targets for the cAMP signal transduction pathway (Tong et al. 2007), virulence and pathogenicity (Staib et al. 2002; Tong et al. 2007), and secondary metabolism (Twumasi-Boateng et al. 2009).

APSES proteins contain a highly conserved domain of approximately 100 amino acids, the so-called APSES domain. The flanking sequences differ significantly within the fungal kingdom and have no known function. The APSES domain has structural similarity to the DNA-binding domain of eukaryotic basic helix-loop-helix (bHLH) proteins, and displays homology with fungal transcription factors involved in cell-cycle regulation (Dutton et al. 1997). The bHLH-type transcription factors are known to form homo- and heterodimers and are able to interact with numerous regulatory cofactors. In $A$. nidulans, StuAp has been found to bind to MluI cell-cycle box (MCB) sequences by in vitro complex formation and by onehybrid experiments (Dutton et al. 1997). MCB sequences is a target DNA consensus for the MCB-binding factor (MBF) composed of heterodimers of bHLH proteins, such as Mbp1p/Swi6p in S. cerevisiae; this MBF complex regulates cell-cycle genes (Koch et al. 1993). APSES proteins could potentially act as both activator and repressor, because of reversible transitions between spherical and filamentous cells (Doedt et al. 2004). The APSES domains is extremely similar among fungi and probably emerged early in fungal evolution from a viral KilA-N precursor that was acquired by the host cell (Iyer et al. 2002). The KilA-N domain is found in a wide range of proteins of large bacterial and eukaryotic DNA viruses.

Fusarium graminearum (sexual stage Gibberella zeae) is an economically important plant pathogen, causing head blight on wheat and barley and stalk and ear rot disease of corn (Goswami and Kistler 2004). The damage caused by the fungus is twofold: in addition to yield and quality losses due to sterility of the florets and formation of discolored, withered and light test-weight kernels, infected grains may contain significant levels of the mycotoxins trichothecene and zearalenone (McMullen et al. 1997), thus making the grain unfit for food or feed due to the regulatory limits on mycotoxin consumption worldwide. These characteristics cause price reduc- 
tion and difficulties for marketing, exporting, and processing of infected grain. With the goal of reducing damage caused by this plant pathogen, the genome of $F$. graminearum has been sequenced, annotated, and compared with other organisms (Cuomo et al. 2007).

During the annotation process of $F$. graminearum, we found four predicted genes with similarity to APSES proteins. Here, we report the functional analysis of $\mathrm{FgStuA}$, an $\mathrm{F}$. graminearum gene encoding a protein with homology to the best-described APSES transcription factor in other fungi, StuAp. We wanted to see whether some of the conserved phenotypes of stuA mutants reported in other fungi also were found in $F$. graminearum, and to find functions specific to $F$. graminearum. Targeted deletion suggests that FgStuAp is involved in regulation of several developmental processes, especially necessary for spore development, pathogenicity, and secondary metabolism in $F$. graminearum; mechanisms which also where found in some of the other stuA mutants in other fungal species. We did global gene expression studies under three conditions to see whether we were able to find genes directly regulated by FgStuAp, and common and unique regulatory processes of FgStuAp compared with other fungi. Microarray analysis on the wild type and $\Delta F g S t u A$ deletion mutant during asexual sporulation (liquid carboxymethylcellulose [CMC]), after wheat head inoculation, and on a secondary metabolite-inducing media (secondary metabolism [SecMet]) show that thousands of genes are directly or indirectly affected by FgStuAp. The high number of differentially regulated genes makes it impossible to separate direct and indirect effects from the lack of FgStuAp. In S. cerevisiae, transcriptional regulators within a functional category (for example, cell cycle) were often bound to genes encoding other transcriptional regulators (Lee et al. 2002), and this cascade could be an explanation to the high number of genes differentially expressed in $\triangle F g S t u A$. We also studied the StuAp response element in A. nidulans "A/TCG CGT/ANA/C", which was found significantly enriched in cellcycle promoters in the $F$. graminearum genome sequence.

\section{RESULTS}

\section{FgStuA encodes an APSES-type transcription factor.}

The APSES proteins, like FgStuAp, are key regulators of fungal development in several species (Ramirez-Zavala and Dominguez 2008). The open reading frame of FgStuA (FGSG_10129) consists of $2,487 \mathrm{bp}(2,031 \mathrm{bp}$ in the coding sequence), comprising four exons and three introns (Supplementary Fig. S1a). The predicted FgStuAp protein is 676 amino acids in length, with a predicted mass of $74.2 \mathrm{kDa}$ and an isoelectric point of 6.47. Pfam database searches pointed to the presence of a conserved APSES-type DNA binding domain (pfam02292), and showed the existence of putative homologues in several filamentous fungi, including $A$. fumigatus, $A$. nidulans, Botryotinia fuckeliana, C. albicans, Chaetomium globosum, Exophiala dermatitidis, F. oxysporum, Glomerella cingulata, Magnaporthe grisea, N. crassa, N. africana, Podospora anserina, Penicillium marneffei, S. cerevisiae, Sclerotinia sclerotiorum, and Yarrowia lipolytica. The FgStuAp protein sequence showed the highest homology with FoStuAp in $F$. oxysporum, with $72 \%$ identical amino acids and $78 \%$ positives $(E=0)$.

We compared gene expression levels of the $\mathrm{FgStuA}$ gene and three other genes (FGSG_04220, FGSG_05283, and FGSG_ 10384) with interpro (IPR003163) APSES protein in $\bar{F}$. graminearum, using published expression data from Plexdb (www.plexdb.org) and unpublished data from a $\mathrm{PH}-1$ wheat infection series and germinating ascospores in liquid complete medium (CM) (Supplementary Fig. S2). We found that FgStuA is constitutively expressed during all conditions tested, with high expression levels during nitrogen starvation. Expression of the other three APSES genes was coregulated under some conditions but was not significantly affected by the FgStuA deletion.

\section{Morphology and sporulation.}

In order to study the function of $\mathrm{FgStuA}$, we deleted the gene using the split marker method (Catlett et al. 2003) (Fig. 1A). Transformants were verified by Southern (Fig. 1B and C) and polymerase chain reaction (PCR) (Fig. 1D). Deletion of FgStuA produced radical phenotypic changes in sporulation, pathogenicity, and secondary metabolite production. In culture, the wild-type $\mathrm{PH}-1$ strain produced red pigment on V8 and potato dextrose agar (PDA) agar, large quantities of macroconidia, and aerial mycelia. In contrast, the $\Delta F g S t u A$ strain showed a white or yellow colony phenotype (on V8 medium or PDA agar medium, respectively), with stunted mycelium embedded in the solid media. The $\triangle F g S t u A$ had a radial growth of $3.12 \pm 0.23 \mathrm{~cm}$ on minimal media (MM) after 3 days at room temperature whereas wild-type $\mathrm{PH}-1$ measured $4.72 \pm 0.16$ $\mathrm{cm}$. Cultures of the $\triangle F g S t u A$ mutant produced few macroconidia on sporulation medium (CMC). After 62 h, only $90 \pm 60$ macroconidia/ml were obtained from the $\triangle F g$ StuA mutant, in contrast to $1.1 \pm 0.38 \times 10^{6} \mathrm{macroconidia} / \mathrm{ml}$ in $\mathrm{PH}-1$. The wild type produced macroconidia on solitary phialides or on multiple phialides borne on conidiophores (Fig. 2A); the mutant failed to form conidiophores or phialides and, instead, appeared to produce spores directly from hyphae (Fig. 2B). The mutant macroconidia germinated at a slower rate than the wild type, approximately $4 \mathrm{~h}$ later than the wild type at $25^{\circ} \mathrm{C}$ in liquid CM without shaking. In addition, under conditions where the wild type produced conidiophores (Fig. 2C), $\Delta F g S t u A$ hyphae developed bulbous, chitin-rich regions in the hyphae

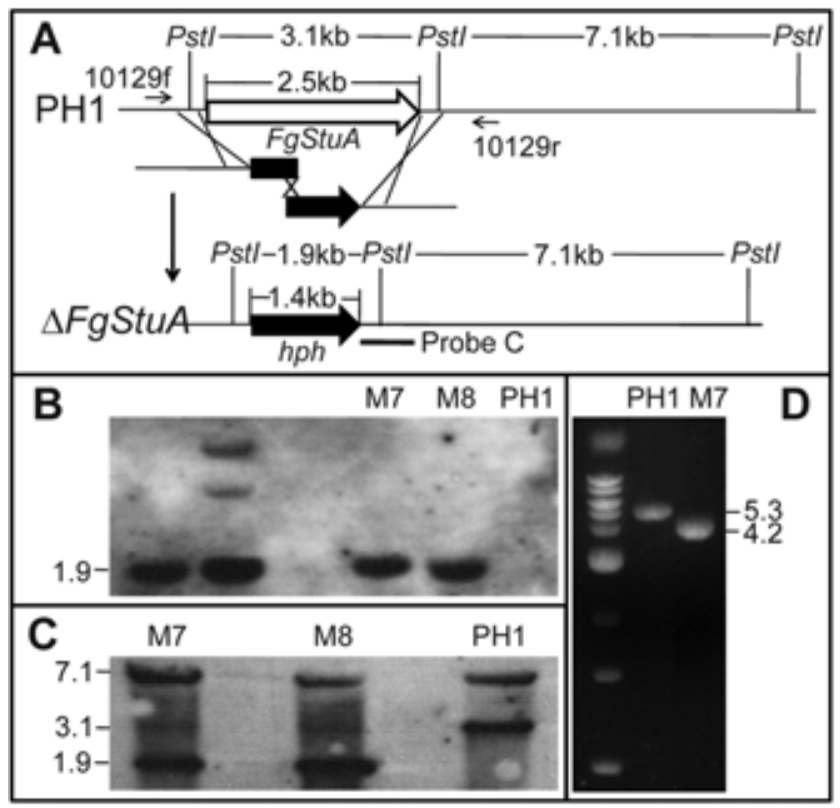

Fig. 1. Deletion of the FgStuA gene from Fusarium graminearum. A, Illustration of the split marker protocol for constructing the FgStuA deletion. Restriction sites, hybridization probes, and screening primers are indicated. B and $\mathbf{C}$, Southern blot of genomic DNA from $\Delta F g S t u A$ mutants (M7 and M8) digested with PstI, using B, a hph probe amplified with primers $\mathrm{HY} 1 \mathrm{~F}$ and $\mathrm{YG} 2 \mathrm{R}$ and $\mathbf{C}$, a right flank probe amplified with primers 10129-3F and 10129-4R. D, Polymerase chain reaction of the $\Delta F g S t u A$ M7 mutant (used for all subsequent experiments) using primers 10129f and 10129r indicates deletion of the FgStuA gene. 
(Fig. 2D). The mutant produced neither perithecia nor ascospores by selfing, nor was it able to sexually cross with wildtype or other strains (results not shown). The summary of all $\Delta F g S t u A$ phenotypes is described in Table 1 .

\section{Loss of pathogenicity.}

To investigate the role of FgStuAp on pathogenicity, the ability to cause symptoms was evaluated on wheat cv. Norm. No symptoms could be identified in the $\Delta F g S t u A$ or mockinoculated plants whereas wild-type $\mathrm{PH}-1$ showed tissue bleaching and deformed awns (Fig. 3A). On 10 replicate heads, the disease level from the wild type scored 6.2 \pm 2.7 (10 is maximum disease) 14 days after inoculation, whereas the $\triangle F g S t u A$ mutant and the mock-inoculated control scored zero on all 10 replicates. The $\Delta F g S t u A$ strain was isolated from the infected spike, proving its ability to survive inside the plant tissue but inability to cause symptoms on it. The $\Delta F g$ StuA mutant also showed reduced colonization on apple (Fig. 3B and C). Together, this illustrates that disruption of $F g S t u A$ impairs the pathogenic ability of $F$. graminearum.

\section{Secondary metabolism is reduced.}

One of the most noticeable phenotypes of the $\Delta F g S t u A$ mutant was the reduction in the red pigment aurofusarin on both V8 and PDA agar (Fig. 4A). The wild type showed the typical red pigmentation but the mutant was white (on V8) or yellow (on PDA). The ability of $\Delta F g S t u A$ to produce trichothecenes also was assayed both in culture and in planta. On SecMet medium, the amount of 15-acetyldeoxynivalenol (15ADON) produced by $\Delta F g S t u A$ was measured to be $<1 \%$ of the wild-type level (Fig. 4B) whereas deoxynivalenol (DON) was not detected in the mutant (Fig. 4C). Under the same conditions, the wild-type strain produced $15 \mathrm{ADON}$ at approximately $525 \mathrm{ppm}$ and DON at approximately $7.5 \mathrm{ppm}$ in the culture media. During wheat infection, the wild-type strain produced $15 \mathrm{ADON}$ at approximately100 ppm (Fig. 4D) and DON at approximately 300 ppm (Fig. 4E), whereas no trichothecenes were detected in the mutant in any of the 10 replicate spikelets.

\section{Gene expression experiments during sporulation, toxin production, and wheat infection.}

Sporulation $(C M C)$. To try to identify genes regulated by FgStuAp during sporulation, gene expression levels were monitored for the mutant and the wild type on a medium conducive

Table 1. Summary of $\Delta F g S t u A$ phenotypes ${ }^{\mathrm{a}}$

\begin{tabular}{lll}
\hline Parameters $^{\mathbf{b}}$ & \multicolumn{1}{c}{$\boldsymbol{\Delta F \boldsymbol { F S t u A }}$} & \multicolumn{1}{c}{ PH-1 } \\
\hline Macroconidia $^{\mathrm{c}}$ & $90 \pm 60$ & $1.1 \pm 0.38 \times 10^{6}$ \\
Germination of conidia (h) $^{\mathrm{d}}$ & 12 & 8 \\
Radial growth $^{\mathrm{d}}$ & $3.12 \pm 0.23$ & $4.72 \pm 0.16$ \\
Conidiophores $_{\text {Perithecia and ascospores }}$ & nd & Yes \\
Mycelia on V8 and PDA & Stunted & Yes \\
V8 media color & White & Aerial \\
PDA color & Yellow & Red \\
Wheat disease level & Zero on all heads & Red \\
Apple colonization & $<$ Wild type & Yes \\
15ADON & $<1 \%$ than wild type & $\approx 525$ ppm \\
DON & nd & $\approx 300$ ppm \\
Chitin content & Reduced & Control \\
No. of septa in macroconidia & Reduced & Control \\
Catalase activity & Reduced & Control \\
Hydrophobicity & Reduced & Control \\
\hline
\end{tabular}

${ }^{\mathrm{a}}$ nd $=$ Not detected.

${ }^{\mathrm{b}} \mathrm{PDA}=$ potato dextrose agar, $15 \mathrm{ADON}=15$-acetyldeoxynivalenol production in media, and DON = deoxynivalenol production in wheat.

${ }^{\mathrm{c}}$ Number of spores/ml after $62 \mathrm{~h}$ of growth on carboxymethylcellulose media.

${ }^{\mathrm{d}}$ Radial growth on minimal media in $\mathrm{cm}$ after 3 days at room temperature.

e On 10 replicate heads 14 days after inoculation (0 to 10).

${ }^{\mathrm{f}}$ In macroconidia and germlings.

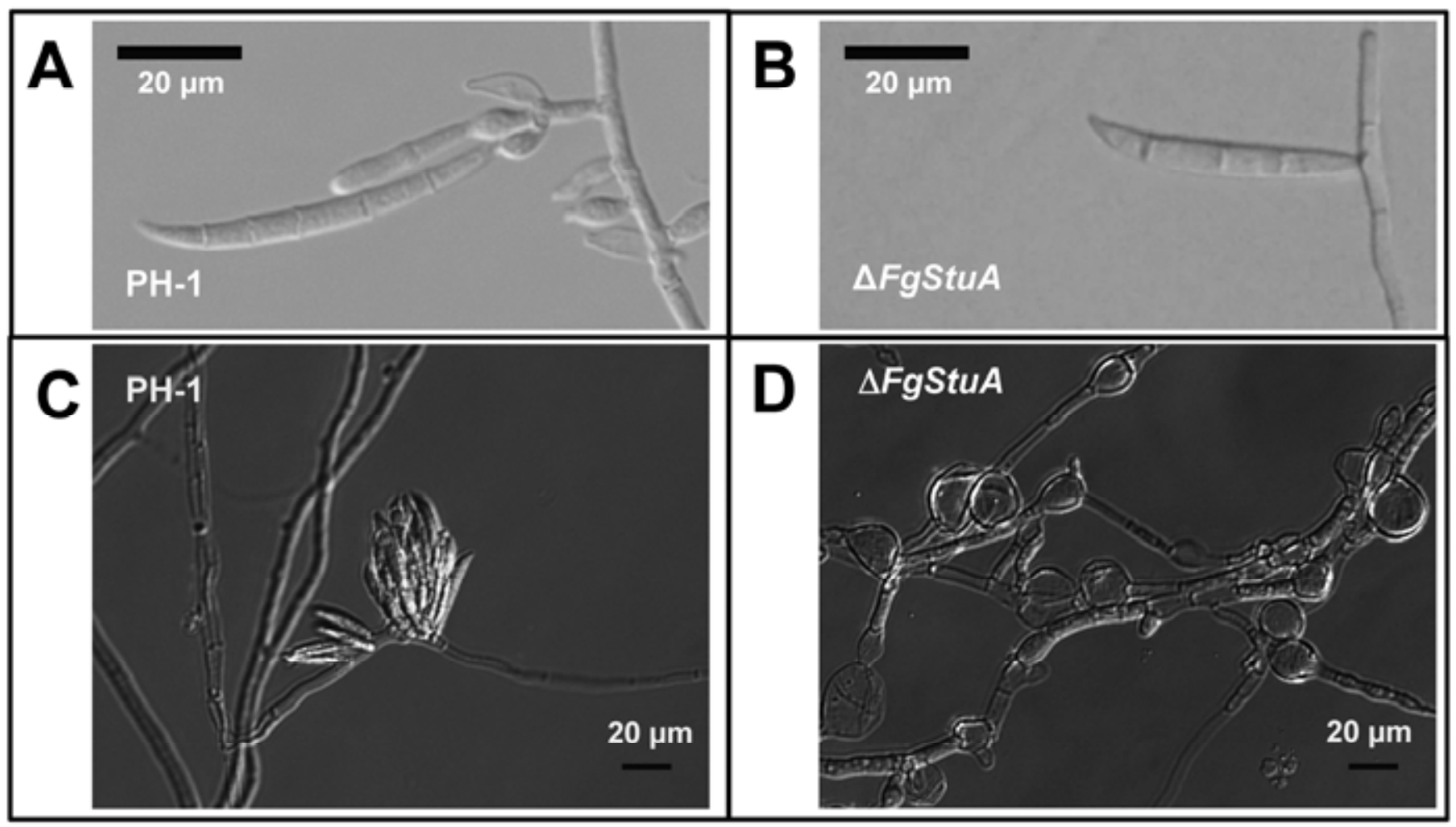

Fig. 2. Spore production in $\Delta F g S t u A$. A, Wild-type strain PH-1 produces abundant macroconidia borne on phialides while $\mathbf{B}$, the $\Delta F g S t u A$ mutant fails to form conidiophores or phialides and produces aberrant macroconidia directly from hyphae. $\mathbf{C}$, At the time when the wild type produces conidiophores and phialides, the $\triangle F g S t u A$ mutant produces swollen chitin-rich cells in the mycelia, $\mathbf{D}$, reflecting an anomalous developmental program. 
to spore production, CMC. After $24 \mathrm{~h}, \mathrm{PH}-1$ produced large numbers of macroconidia in all three replicates $(1.9 \pm 0.2 \times$ $10^{5}$ macroconidia/ml), whereas no conidia could be found in any of the mutant replicates. Global gene expression was compared on total RNA obtained from $\mathrm{PH}-1$ and $\Delta F g S t u A$ mycelia. To enrich for expression differences in conidiogenous hyphae rather than simply identify genes expressed in spores themselves, the cultures were filtered through Miracloth and washed extensively to get rid of spores prior to RNA isolation. The total catalog of expressed genes and those differentially expressed greater than twofold between the mutant and the wild type were noted and categorized according to predicted function. At $P$ value $=0.04$, the total number of expressed probesets in PH-1 was 9,932 and, in $\Delta F g$ StuA, 10,169 (Table 2). There was a surprisingly high number of differentially expressed genes on the CMC media, where 2,952 genes had a higher expression in $\Delta F g$ StuA and 2,471 had a higher expression in the wild-type strain. From those with higher expression in the wild-type strain, putative genes involved in macroconidia production can be found, such as the trehalose synthase (FGSG_04456) and putative orthologs to the Aspergillus genes FluG (FGSG_10043), FlbB (FGSG_01313), and FldD (FGSG_01915).

Compared with the genome as a whole, the probesets with higher expression in $\mathrm{PH}-1$ on $\mathrm{CMC}$ were especially enriched $(P=0)$ in MIPS (Munich Information Center for Protein Sequences) category 99, "Unclassified proteins". Of 2,952 probesets, 1,544 probesets $(74.1 \%)$ were unclassified, reflecting the limited knowledge of genes involved in spore production. Other categories of probesets with significantly higher expression in $\mathrm{PH}-1$ were genes involved in " $\mathrm{C}$-compound and carbohydrate metabolism" (MIPS category 01.05; $P=9.43 \mathrm{E}-5$ ), "Polysaccharide binding" (MIPS category 16.05; $P=0.0005$ ), "Extracellular metabolism" (MIPS category 01.25; $P=0.001$ ), and "Disease, virulence, and defense" (MIPS category 32.05; $P=0.0026)$. Expression data suggest that carbohydrate sources

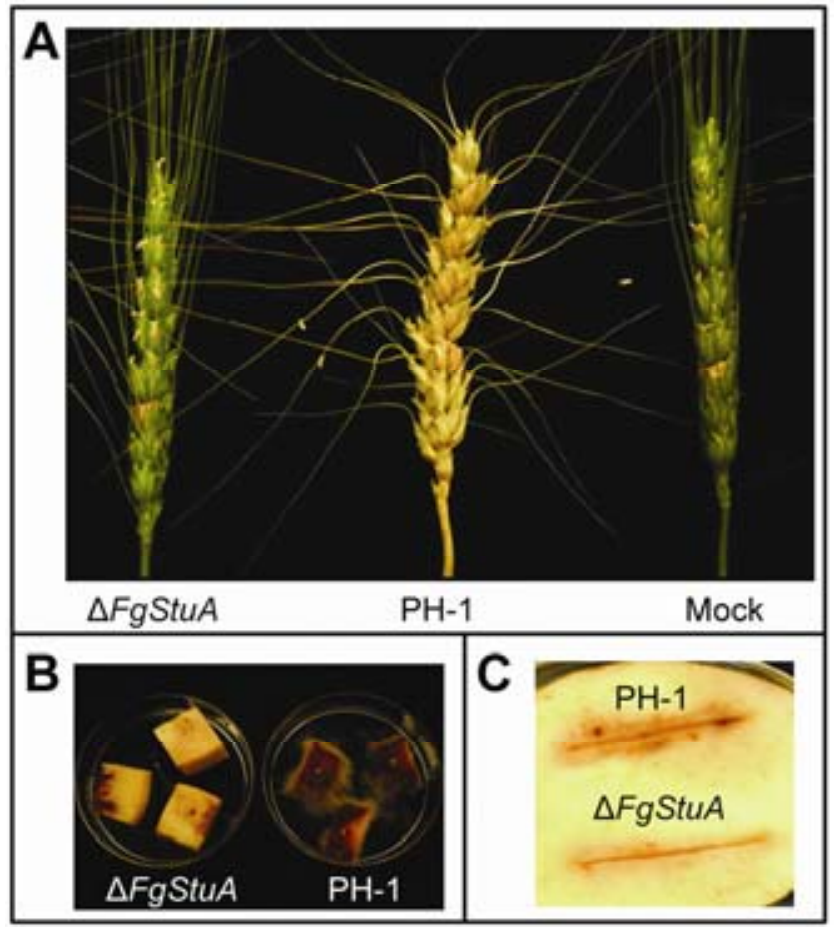

Fig. 3. Pathogenicity of $\Delta F g S t u A$. A, Pathogenicity test on the wheat cv. Norm. The wild type causes tissue bleaching and deformed awns on infected spikes. No symptoms could be found in plants inoculated with the $\Delta F g$ StuA mutant or mock inoculated plants. $\mathbf{B}$ and $\mathbf{C}$, Apple tissue inoculated with mutant and wild type after 3 days of incubation. in the CMC media were utilized for production of macroconidia, where several putative enzymes were found with higher expression in the wild type, such as amylase (FGSG_03842), maltase (FGSG_03703 and FGSG_03890), mannosidase (FGSG_00807, FGSG_02314, FGSG_04679, FGSG_04930, and FGSG_09931), galactosidase (FGSG_02059, FGSG_ 03904, and FGSG_11032), and glucosidase (FGSG_02632, FGSG_03387, FGSG_03462, FGSG_03703, FGSG_03890, FGSG_04913, FGSG_04953, FGSG_05292, FGSG_06278, FGSG_06605, FGSG_07274, FGSG_08757, and FGSG_ 11326).

Probesets with higher expression in $\triangle F g S t u A$ on CMC were especially enriched in the functional categories "Metabolism" (MIPS category $01 ; P=0$ ), "Protein synthesis" (MIPS category $12 ; P=8.04 \mathrm{E}-93)$, "Proteins with binding function or cofactor requirement" (MIPS category $16 ; P=2.34 \mathrm{E}-28$ ), and "Transcription" (MIPS category $11 ; P=1.11 \mathrm{E}-22$ ) (Table 3 ). These categories are very similar to gene expression profiles during swelling and spore activation in macroconidia after $2 \mathrm{~h}$ of incubation in liquid CM (Seong et al. 2008), and suggest that $\triangle F g S t u A$ is delayed in development because the CMC data are from $24 \mathrm{~h}$. The slow radial growth and spore germination in $\Delta F g$ StuA also supports this observation.

Secondary metabolite production also was affected on CMC medium for the $\triangle F g S t u A$ strain. The mutant was reduced in pigmentation on both V8 and PDA media (Fig. 4A), and this was reflected in gene expression on $\mathrm{CMC}$, where 17 adjoining probesets, including all known aurofusarin biosynthetic genes (Frandsen et al. 2006), showed very low expression or were not detected in $\triangle F g S t u A$ compared with $\mathrm{PH}-1$ (Fig. 4F). The $\triangle F g S t u A$ mutant also produced few or no spores on PDA and V8 media compared with the wild type, similar to the effect on CMC.

Pathogenicity-inoculated wheat heads. To explain differences in gene expression that could account for loss of pathogenicity in the $\Delta F g S t u A$ mutant, genes expressed during plant colonization were analyzed comparing expression patterns with the wild type. At $P$ value $=0.04$, the total number of expressed probesets in wheat was 6,184 for PH-1 and 2,638 for $\triangle F g$ StuA (Table 2), likely reflecting the poor growth of the mutant in planta, as seen in the pathogenicity assays. The high number of expressed $\mathrm{PH}-1$ probesets reflects the complex biological machinery needed to cause disease in wheat. Only 242 probesets showed higher expression in $\triangle F g S t u A$ during survival on wheat, in contrast to 4,293 that were higher in PH-1. The probesets with higher expression in $\triangle F g S t u A$ on wheat where especially enriched $(P=4.17 \mathrm{E}-6)$ in MIPS category 99 , "Unclassified proteins" (82.3\%). The probesets with higher expression in $\mathrm{PH}-1$ were significantly enriched in most functional categories (Table 3) such as: "Metabolism" (MIPS category $01, P=0$ ), "Protein with binding function or cofactor requirement" (MIPS category $16 ; P=0$ ), and "Cellular transport, transport facilities and transport routes" (MIPS category $20 ; P=0)$ as well as "Protein synthesis" (MIPS category 12; $P=3.54 \mathrm{E}-67$ ), "Protein fate" (MIPS category $14 ; P=7.15 \mathrm{E}-$ 43 ), and "Transcription" (MIPS category $11 ; P=5.29 \mathrm{E}-32$ ).

Table 2. Number of genes expressed in the three experiments ${ }^{\mathrm{a}}$

\begin{tabular}{lrrr}
\hline Parameters & CMC & Wheat & SecMet \\
\hline Total expressed $\Delta F g$ StuA & 10,169 & 2,638 & 10,499 \\
Total expressed PH-1 & 9,932 & 6,184 & 10,250 \\
Higher expressed $\Delta F g$ StuA (>twofold) & 1,586 & 39 & 417 \\
Higher expressed PH-1 (>twofold) & 1,342 & 538 & 462 \\
Expressed only in $\Delta F g S t u A$ & 1,366 & 203 & 746 \\
Expressed only in PH-1 & 1,129 & 3,755 & 495 \\
\hline
\end{tabular}

${ }^{\mathrm{a}} \mathrm{CMC}=$ carboxymethylcellulose and SecMet $=$ secondary metabolism. 
The gene expression levels of the known trichothecenerelated genes were also highly affected in $\Delta F g S t u A$. In wheat, the wild type showed high expression levels in most of the genes but no activity in any of the genes could be found in the mutant (Fig. 4G). This correlates with the chemical analysis, where no DON or $15 \mathrm{ADON}$ could be found in the $\Delta F g S t u A$ inoculated wheat spikelets.
SecMet. On SecMet media, the total number of expressed probesets was 10,250 for $\mathrm{PH}-1$ and 10,499 for $\Delta F g$ StuA, at $P$ value $=0.04$ (Table 2$)$. There were 1,163 probesets with higher expression in $\Delta F g S t u A$ and 957 with higher expression in PH-1. When sorting the functional categories according to $P$ value, the genes with higher expression in $\Delta F g S t u A$ were weakly enriched in "Amino acid/amino acid derivatives transport" (MIPS

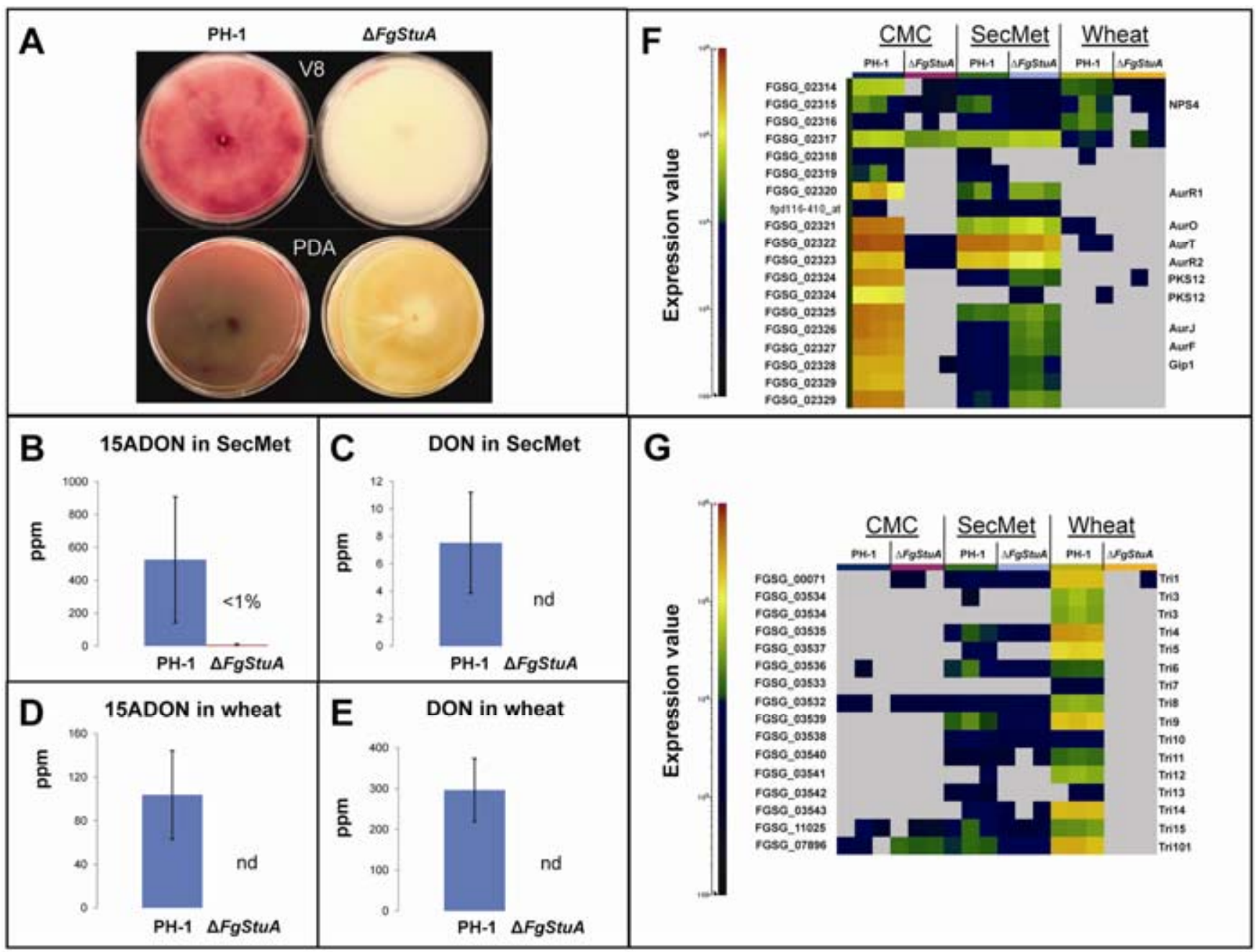

Fig. 4. Secondary metabolite production in $\Delta F g S t u A$. A, Comparison of pigment production by PH-1 and $\Delta F g S t u A$ on V8 and potato dextrose agar (PDA) media. B to E, Production of the trichothecenes B, 15-acetyldeoxynivalenol (15ADON) and C, deoxynivalenol (DON) on the secondary metabolism (SecMet) media and $\mathbf{D}$ and $\mathbf{E}$, on wheat heads; nd = not detected. Expression map of $\mathbf{F}$, aurofusarin- and $\mathbf{G}$, trichothecene-related genes during growth on carboxymethylcellulose (CMC), SecMet, and wheat; gray signals = not detected.

Table 3. Presence of the StuAp-binding motif A/TCGCGT/ANA/C from Aspergillus spp. in promoter sequences of genes belonging to MIPS Functional Category 10 "Cell cycle and DNA processing" in Fusarium graminearum, Neurospora crassa, and Saccharomyces cerevisiae ${ }^{\mathrm{a}}$

\begin{tabular}{|c|c|c|c|}
\hline \multirow[b]{2}{*}{ Species, motifs } & \multicolumn{2}{|c|}{ Motifs present (\%) } & \multirow[b]{2}{*}{$P$ value $^{\mathrm{b}}$} \\
\hline & In cell-cycle promoters & In all promoters & \\
\hline F. graminearum & $296 / 652(45)$ & $4,440 / 13,332(33)$ & $5.56 \mathrm{E}-11$ \\
\hline N. crassa & 291/622 (47) & $3,367 / 9,825(34)$ & $1.69 \mathrm{E}-11$ \\
\hline S. cerevisiae & $279 / 1012(28)$ & $1,122 / 5,881(19)$ & $3.68 \mathrm{E}-12$ \\
\hline \multicolumn{4}{|c|}{ Sequences with StuAp-binding motifs ${ }^{c}$} \\
\hline F. graminearum (4-8 motifs) & $22 / 652(3.37)$ & 204/13,332 (1.53) & $1 \mathrm{E}-4$ \\
\hline N. crassa (4-9 motifs) & $22 / 622(3.54)$ & $153 / 9,825(1.56)$ & $7 \mathrm{E}-5$ \\
\hline S. cerevisiae (4-8 motifs) & $11 / 1012(1.09)$ & $35 / 5,881(0.595)$ & $4 \mathrm{E}-2$ \\
\hline
\end{tabular}

${ }^{a}$ Promoter sequences $=1,000$ nucleotides upstream of genes for $F$. graminearum and $N$. crassa and 500 nucleotides upstream for $S$. cerevisiae. MIPS $=$ Munich Information Center for Protein Sequences.

${ }^{\mathrm{b}}$ Calculated using a $\chi^{2}$ test to find if promoter sequences of genes in the MIPS Functional Category "Cell cycle and DNA processing" are enriched in the StuAp binding motif A/TCGCGT/ANA/C from Aspergillus.

${ }^{c}$ Promoter sequences with the highest number of StuAp-binding motifs, and corresponding genes found in the functional category "Cell cycle and DNA processing". 
category 20.01.07; $P=0.002)$, "Unclassified proteins" (MIPS category 99; $P=0.003$ ), "Non-vesicular cellular import" (MIPS category 20.09.18.07; $P=0.0046$ ), and "Sugar transport" (MIPS category 20.01.03.01; $P=0.0056$ ) (Table 3). The genes with higher expression in $\mathrm{PH}-1$ were enriched in "Unclassified proteins" (MIPS category 99; 2.41E-7), "Virulence, disease factors" (MIPS category 32.05.05; $P=6.76 \mathrm{E}-5$ ), "Fatty acid metabolism" (MIPS category 01.06.05; $P=0.0002$ ), "Toxins" (MIPS category 32.05.05.01; $P=0.002$ ), and "Secondary metabolism" (MIPS category 01.20; $P=0.0056$ ). This, together with the trichothecene toxin data, indicates that
SecMet medium could be useful for secondary metabolite screening in Fusarium spp. According to MIPS FunCat, the number of genes associated with secondary metabolites (including toxins) was 36 in $\mathrm{PH}-1$ and 22 in $\Delta F g S t u A$ on the SecMet media. It seems that secondary metabolite production in all three experiments was reduced in $\triangle F g S t u A$.

Summary expression data. Enriched functional categories for each experiment are shown in Figure 5A. Principal component analyses (PCA) show that the difference in expression profile between the wild type and mutant is greatest during sporulation and pathogenicity (Fig. 5B and C). The detailed

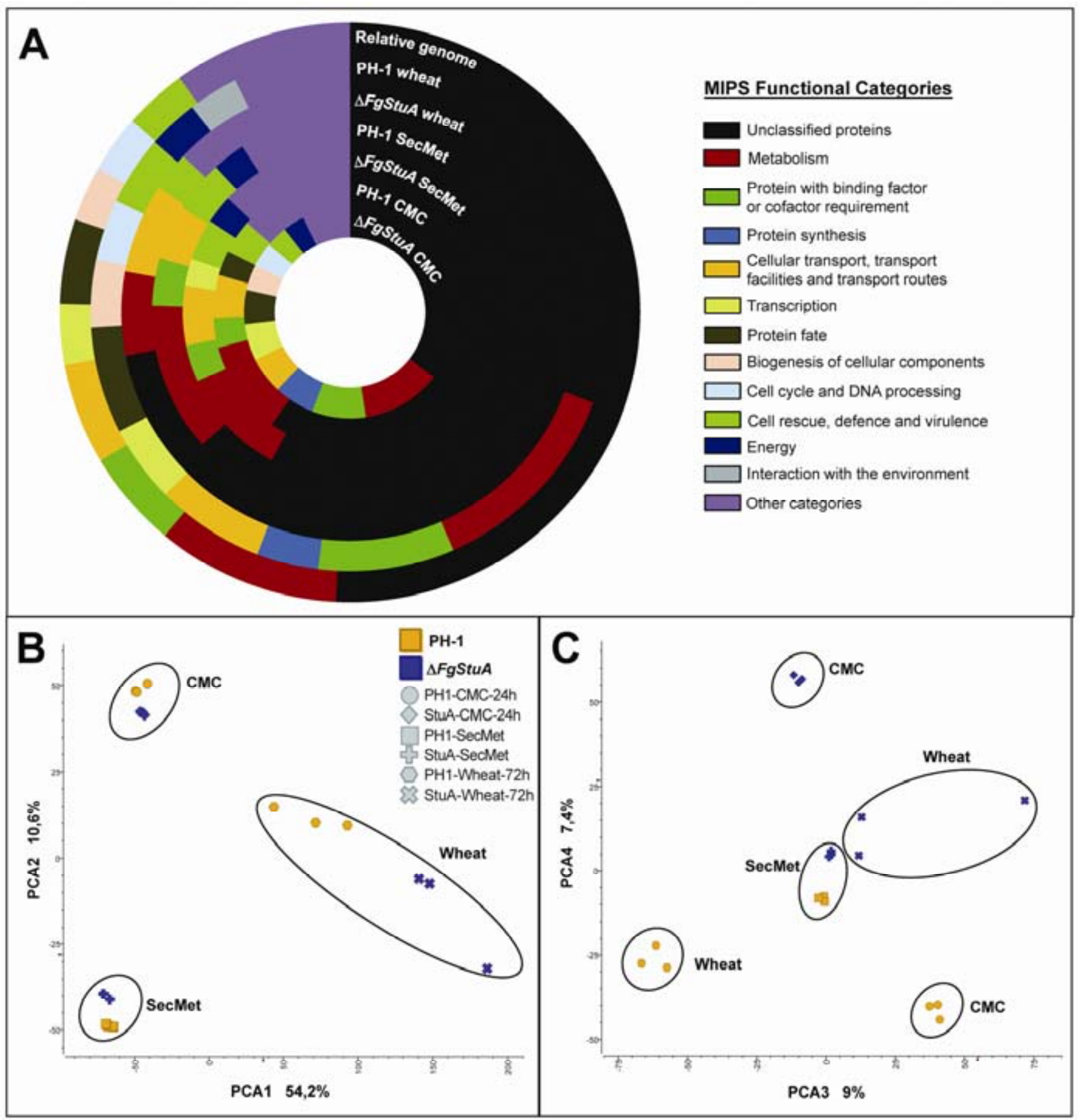

Fig. 5. MIPS FunCat and principal component analyses (PCA) of the experiments. A, MIPS functional analysis of the genes differentially expressed in $\triangle F g$ StuA and PH-1 on carboxymethylcellulose (CMC), secondary metabolism (SecMet), and wheat. Number of genes used: on CMC $(\triangle F g S t u A=2,952, \mathrm{PH}-1=$ $2,471)$, SecMet $(\Delta F g S t u A=1,163, \mathrm{PH}-1=957)$, and wheat $(\Delta F g S t u A=242, \mathrm{PH}-1=4293)$. B and $\mathbf{C}$, PCA of the items (probesets) comparing the relationship between the three experiments. 
expression data for all genes and functional categories can be found in Supplementary Tables S1, S2, and S3.

Chitin and glucan metabolism is affected.

Among the genes significantly more highly expressed in the wild type than mutant on CMC were those related to chitin
(Fig. 6A) and glucan synthesis. We found 25 genes associated with glucan metabolism more highly expressed in $\mathrm{PH}-1$ than in $\triangle F g$ StuA on $\mathrm{CMC}$, in contrast to only 5 that were more highly expressed in the mutant. Genes encoding chitin-binding proteins were not significantly expressed in the mutant, and several chitin synthase genes and a chitinase were expressed at

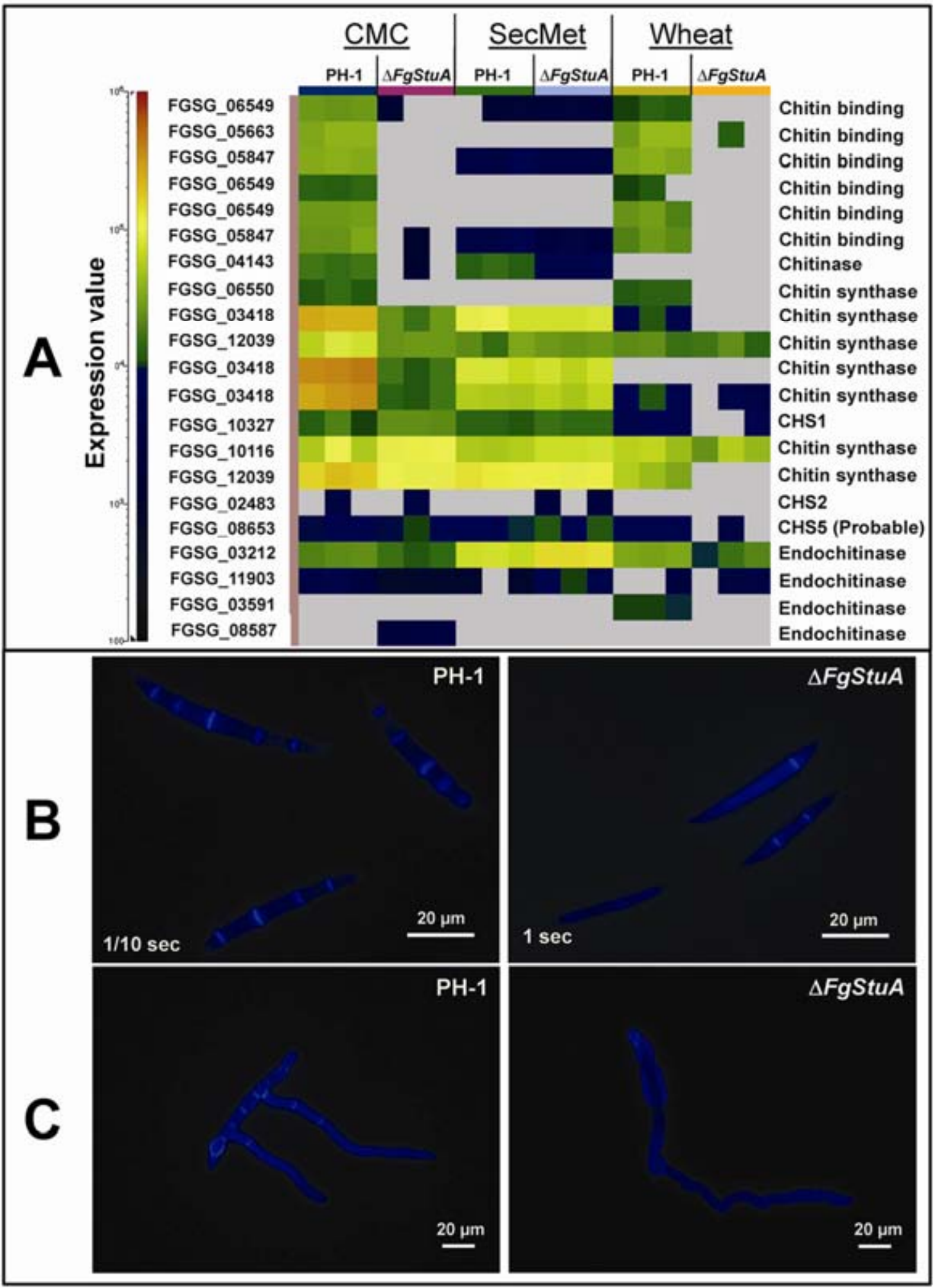

Fig. 6. Expression of chitin-related genes and staining of chitin in spores and germlings. A, Expression heat map of genes related to chitin metabolism in $\triangle F$ SStuA and PH-1 on carboxymethylcellulose (CMC), secondary metabolism (SecMet), and wheat; gray signal = not detected. $\mathbf{B}$ and $\mathbf{C}$, Chitin-binding compound calcoflour was used to stain spores and germlings of mutant and wild-type strains. A 10 -fold longer exposure time was needed for the $\Delta F g S t u A$ mutant to achieve levels of florescence similar to the wild-type conidia. Mutant spores form fewer septa at more irregularly spaced intervals. 
significantly lower levels. Chitin and glucan are major components of the conidial cell wall (Schmit and Brody 1976), and the lower expression levels of genes involved in wall synthesis might be expected for the mutant, which did not produce spores. To determine whether reduced gene expression for chitin metabolism was reflected in reduced chitin content of walls, spores and germlings were treated with the chitin-binding stain calcofluor. There was a clearly diminished calcofluor affinity for both spores and germlings of the $\Delta F g$ StuA mutant compared with the wild type (Fig. 6B and C), suggesting that macroconidial cell walls in $\Delta F g S t u A$ contain a lower amount of chitin. The staining also showed that the mutant conidia had a diminished number of septa, which resulted in irregularsized conidial cells, which became more pronounced in germinating conidia compared with the relatively uniform size of wild-type cells. Chitin metabolism seems to be affected as a result of deletion of the $F g S t u A$ gene in $F$. graminearum.

\section{Catalase activity and hydrophobicity.}

Catalase production has been reported to be deficient in $s t u A$ mutants of $A$. nidulans and A. fumigatus (Scherer et al. 2002; Sheppard et al. 2005). In $\Delta F g S t u A$, the genes encoding several putative catalases (catalase A peroxisomal and catalase isozyme P) were not expressed at all on CMC media and showed lower expression on SecMet media (Fig. 7A). Furthermore, the capacity of $\Delta F g S t u A$ to break down hydrogen peroxide $\left(\mathrm{H}_{2} \mathrm{O}_{2}\right)$ is reduced. The concentration of $\mathrm{H}_{2} \mathrm{O}_{2}$ decreased more rapidly over time for PH-1 spores than for $\triangle F g S t u A$ (Fig. 7B and C). In the linear phase, the wild type had a slope of $-1 \mathrm{E}-5$ and $\triangle F g S t u A$ had a slope of $-6 \mathrm{E}-6$, suggesting that catalase activity is negatively affected by lack of the FgStuAp protein.

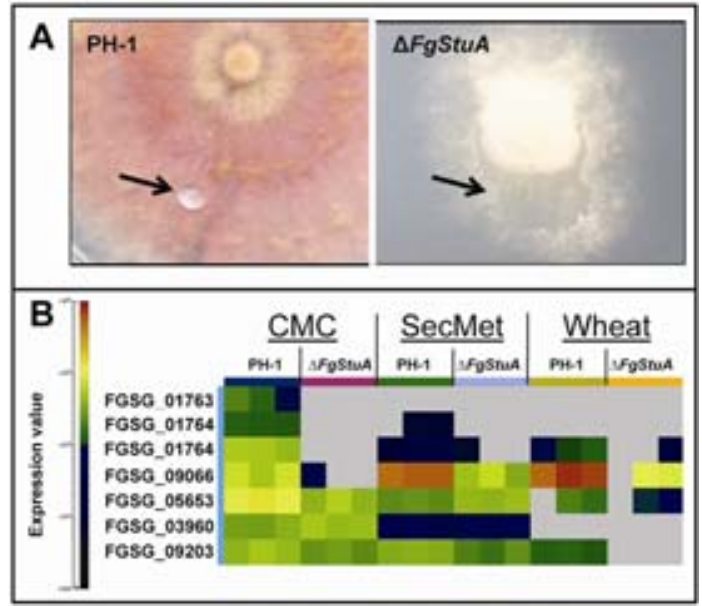

Fig. 8. Hydrophobicity of $\Delta F g S t u A$. A, Hydrophobic character of the mutant and wild-type cultures grown on V8 agar, measured $15 \mathrm{~s}$ after deposition of the water droplet. B, Expression of putative hydrophobin genes on carboxymethylcellulose (CMC), secondary metabolism (SecMet), and wheat; gray signals $=$ not detected.

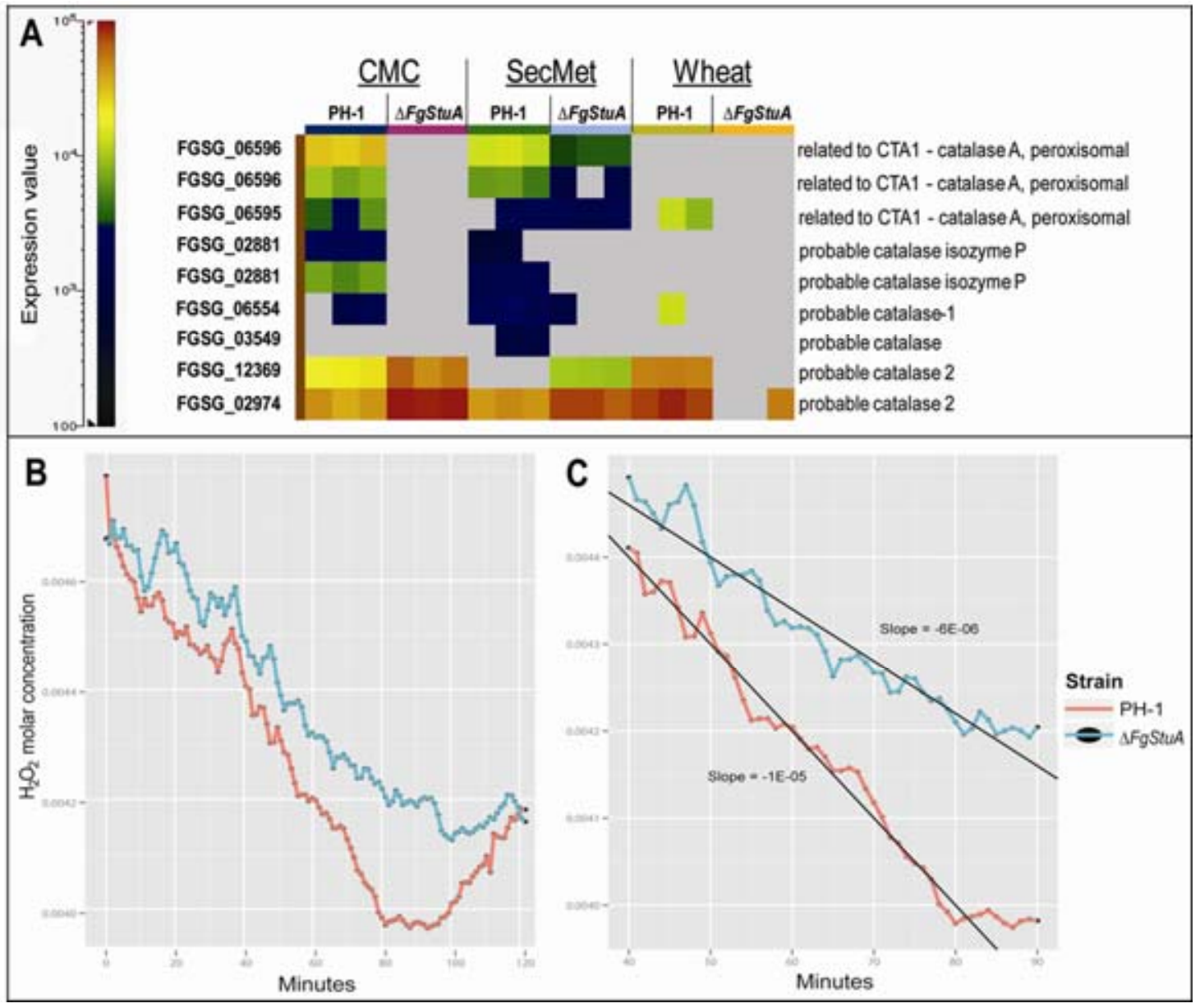

Fig. 7. Expression of catalase genes and degradation of $\mathrm{H}_{2} \mathrm{O}_{2}$ using fungal conidia. A, Expression of catalase genes in PH-1 and $\Delta F g$ StuA during three different conditions; on carboxymethylcellulose (CMC) medium, on secondary metabolism (SecMet) medium, and during wheat infection; gray signals = not detected. B, Degradation of $\mathrm{H}_{2} \mathrm{O}_{2}$ over time inferred by reduced light absorbance at $240 \mathrm{~nm}$. Fungal spores $\left(10^{5} / \mathrm{ml}\right)$ of PH-1 and $\Delta F g S t u A$ were suspended in a solution of $5 \mathrm{mM} \mathrm{H}_{2} \mathrm{O}_{2}$. Absorbance of the solution was read every minute for a total of $120 \mathrm{~min}$, and the graph shows an average of three replicates. $\mathbf{C}$, In the linear phase, the wild type had a slope of $-1 \mathrm{E}-5$ and $\Delta F g S t u A$ had a slope of $-6 \mathrm{E}-6$. Results show that PH-1 catalyses $\mathrm{H}_{2} \mathrm{O}_{2}$ more rapidly than $\Delta F g$ StuA. 
The aerial mycelial surface of $\Delta F g S t u A$ mutant colonies also showed a reduced level of hydrophobicity compared with the wild type. A water droplet placed on the surface of a wild-type colony will form a discrete "bead" that will persist for several minutes, due to the hydrophobic nature of the mycelia surface. On the other hand, the colony surface of the mutant appears to be more "wettable," because a drop placed on the surface of the $\Delta F g$ StuA colony (Fig. 8A) disperses in less than $5 \mathrm{~s}$. Several putative hydrophobin genes showed significantly lower expression in the mutant, especially on the CMC media (Fig. 8B).

\section{The Aspergillus StuAp binding site "A/TCGCGT/ANA/C" is enriched in cell-cycle promoters.}

To examine the putative primary function of FgStuAp, enriched FgStuAp promoter binding sites were investigated. Dutton and associates (1997) reported that the sequence of the StuAp response element in A. nidulans was "A/TCGCGT/ ANA/C". Searching the $F$. graminearum genome, we found that promoter sequences of genes in the MIPS category "Cell cycle and DNA processing" were especially enriched in the motif A/TCGCGT/ANA/C compared with all the promoter sequences in the genome (Table 3). In fact, 10.7\% of the 204 genes with the highest numbers (4 to 8 ) of A/TCGCGT/ ANA/C in their promoter sequences were found in the MIPS category 10 "Cell cycle and DNA processing", in contrast to the genome as a whole, where the cell-cycle genes are only $4.67 \%$ of the total number of genes. We also analyzed promoter sequences from $N$. crassa and $S$. cerevisiae, and the same pattern was found here. Cell-cycle promoters in these three ascomycetes were enriched in the Aspergillus StuApbinding motif. The list of genes with the motif in their promoters and their expression are found in Supplementary Table S4.

Expression data also support the idea that FgStuAp regulates cell-cycle genes. At $P$ value $=0.04$, genes with higher expression in $\triangle F g S t u A$ on $C M C$ media were significantly enriched in the functional category "Cell cycle and DNA processing" (156/614; $P=7.9 \mathrm{E}-5)$ compared with wild-type PH-1 (36/614; $P=1)$. Albeit not significantly, in the SecMet media there were more genes with higher expression in $\triangle F g S t u A$ found in this category; $(31 / 614 ; P=1)$ compared with the wild type $(9 / 614 ; P=1)$. These results suggest that the $A$. nidulans StuAp-binding motifs may be widely conserved not only in $F$. graminearum but also in other ascomycetes such as $N$. crassa and $S$. cerevisiae. This also suggests that FgStuAp could function as a negative regulator of expression. We found that deletion of FgStuA significantly enhanced expression of several neighboring genes (FGSG_10125, clock-controlled protein 6 [CCG-6]; FGSG_10126, acetyl coenzyme A synthetase; FGSG_10127, conserved hypothetical protein; FGSG_10128, hypothetical protein; and FGSG_10130, conserved hypothetical protein) under two of the conditions tested, CMC and SecMet media (Supplementary Fig. S3). This gene cluster also showed synteny with $F$. verticillioides, $F$. oxysporum, and $F$. solani, as well as $N$. crassa.

\section{DISCUSSION}

APSES proteins in ascomycetes have been identified as key regulators of fungal development, controlling processes such as mating, asexual sporulation, and dimorphic growth, and they also participate in the control of virulence traits (RamirezZavala and Dominguez 2008). Fusarium spp. and other filamentous fungi appear to have a single gene orthologous to StuA (The Broad Fusarium comparative database; National Center for Biotechnology Information blastp). Nevertheless, other putative APSES proteins with Interpro IPR003163 mo- tifs exist in $F$. graminearum, such as FGSG_04220 (swi6 ortholog), FGSG_05283, and FGSG_10384 ( $\mathrm{mbpl}$ ortholog). The APSES domain contains a highly conserved bHLH motif of approximately 100 amino acids in the different ascomycetes but the flanking regions showed low similarity. APSES proteins vary considerably in size; the sequences flanking the APSES motif from distantly related yeasts are either nonhomologous or so divergent that any attempts at global alignment are meaningless (Ramirez-Zavala and Dominguez 2008). From the alignment of StuAp sequences, the whole FgStuAp protein sequence showed the highest homology (72\%) with FoStuAp from $F$. oxysporum.

Deletion of FgStuA in $F$. graminearum altered and inhibited conidiophore development and asexual and sexual sporulation. Since its discovery by Clutterbuck (1969), who found StuA in a collection of $A$. nidulans mutants with qualitative effects of conidiophore development, a number of StuA homologs from other fungi have been described, and those mutants also have defects in conidiophore development and, often, deficient in both asexual and sexual sporulation (Aramayo et al. 1996; Borneman et al. 2002; Miller et al. 1992; Ohara and Tsuge 2004; Sheppard et al. 2005; Stoldt et al. 1997; Tong et al. 2007). Similar to $\Delta F o$ StuA in $F$. oxysporum, $\Delta F g$ StuA cells lack conidiophores with uninuclear phialides and produce conidia at much lower frequencies than the wild type directly from the hypha (Fig. 2B). The elongated shape and polar budding pattern of these uninuclear cells strongly resemble those of pseudohyphal cell division in yeasts, where the APSES proteins Phd1p and Efg1p are involved (Gimeno and Fink 1994; Stoldt et al. 1997). In F. oxysporum, microconidia were produced at normal levels and chlamydospore formation was dramatically promoted in the FoStuA mutant but these phenotypes were not observed in $F$. graminearum because neither spore state is produced by this species.

The large number of unclassified genes $(74.1 \%)$ with higher expression in the wild type on CMC medium reflects our lack of knowledge of the molecular mechanism of conidiophore development. Carbohydrate metabolism, extracellular metabolism, and polysaccharide-binding genes related to chitin and glucan metabolism showed higher expression in the wild type. This perhaps reflects the fact that downregulation of these genes in the mutant may inhibit spore formation. Expression of the genes related to chitin binding was, in fact, not detected in the mutant. One defect perhaps attributable to altered chitin metabolism was the reduced and irregular formation of septa in macroconidia of the $\Delta F g S t u A$ mutant. Mutant spores germinated normally but showed more irregular cellular compartments compared with those in the wild type (Fig. 6B and C). During the time when $\mathrm{PH}-1$ produced conidiophores, the $\triangle F g S t u A$ mutant developed aberrant growths resembling chitin-rich "bubbles" within hyphae (Fig. 2D). Perhaps conidiogenous cells in the mutant expand radially rather than form typical cylindrical condiophores. The transcript profile from hyphae of the $\Delta F g$ StuA mutant on CMC for $24 \mathrm{~h}$ was enriched in genes belonging to the functional categories "Metabolism", "Protein synthesis", "Proteins with binding function", and "Transcription" compared with the wild type. This gene expression profile is similar to the wild type during the spore swelling and activation stage $2 \mathrm{~h}$ after suspension in liquid medium (Seong et al. 2008). This could reflect a delayed development of the mutant on CMC medium.

The StuAp transcription factor exerts a complex and contrasting regulatory control over pathogenicity in different fungal species. The $\Delta F g S t u A$ mutant was not pathogenic in wheat heads and did not spread away from the inoculated spikelets. Conversely, an FoStuA mutant in F. oxysporum was fully pathogenic on a susceptible host using a standard conidial 
inoculation of roots (Ohara and Tsuge 2004). Such a great difference in pathogenicity for stuA mutants in different fungal pathogens may be due to different infection routes or strategies of the different Fusarium spp. Where F. oxysporum invades its host (in tomato) by direct hyphal penetration of the root host cells (Olivain and Alabouvette 1999), F. graminearum produces high concentrations of trichothecene toxins during infection of wheat heads through the epicarp, which leads to early cell death and rapid fungal growth through the different layers of the fruit coat (Jansen et al. 2005). In G. cingulata, a fungus that invades its host by means of an appressorium, the FgStuA homolog $G c S t u A$ was shown to be required for pathogenicity on apple (Tong et al. 2007). GcStuA was essential for generation of normal turgor pressure within the appressorium but the mutant without a functional appressorium was still able to infect wounded but not unwounded apple fruit. For Candida spp., the APSES protein Efgl was shown to be involved in adherence to and invasion of host cells and virulence in murine models of disseminated and oral candidiasis (Lo et al. 1997; Stoldt et al. 1997). Thus, APSES proteins may be involved in disease development in unique and unpredictable ways, because fungal development genes can impact key virulence factors in many different ways (Lengeler et al. 2000).

Gene expression during infection of wheat was greatly influenced by $F g S t u A$. Only 2,638 genes were detected during infection of the $\Delta F g S t u A$ mutant compared with 6,184 expressed for wild-type PH-1. The lower number of genes detected for the mutant likely reflects a lower proportion of fungal RNA in infected plant tissue, with fungal genes having lower expression levels being below detection limits in the RNA mixtures. Nevertheless, mutants and the wild type had distinct transcript profiles, and expression levels of some genes in the mutant had higher levels than in the wild type. Most of the genes with higher expression levels in the $\Delta F g S t u A$ mutant $(82.3 \%)$ were in the category "Unclassified Proteins" (MIPS category 99; $P$ $=4.17 \mathrm{E}-6)$. Trichothecene mycotoxins are essential for full virulence and systemic infection of wheat by $F$. graminearum (Jansen et al. 2005); therefore, a major factor in reduced pathogenicity of the $\Delta F g S t u A$ mutant is its inability to produce these toxins in planta (Fig. 4D and E) and the complete loss of trichothecene biosynthetic gene expression during infection (Fig. 4G). However, loss of toxin production probably is not the only reason for loss of pathogenicity because the mutant could not even infect the inoculated spikelet, unlike toxin nonproducing mutants (Jansen et al. 2005). Thousands of genes are expressed at higher levels in wheat by the wild-type strain compared with the $\triangle F g S t u A$ mutant, including genes for predicted pathogenicity factors such as FSRl (FGSG_01665), SID1 (FGSG_05371), and GzGPA2 (FGSG_09614). However, the sheer number of genes differentially regulated by FgStuA makes it very difficult to distinguish cause from effect. Among the enriched functional categories differentially expressed in PH-1 (Fig. 5) was the category for "Cell rescue, defense, and virulence" (MIPS category 32), where 290/655 genes with higher expression in the wild type are found $(P=1.18 \mathrm{E}-16)$ in contrast to $7 / 655$ of the genes with higher expression in the mutant $(P=0.9)$. Therefore, differences in pathogenicity between the mutant and the wild type may be the cumulative effect of differential regulation of hundreds of genes.

Similar to the case of A. fumigatus, where gene clusters for several secondary metabolites, such as sterigmatacystin, gliotoxin, fumigaclavine, fumitremorgin, pseurotin $\mathrm{A}$, and other unknowns, showed lower expression in an stuA mutant (Gravelat et al. 2008; Sheppard et al. 2005; Twumasi-Boateng et al. 2009), deletion of $\mathrm{FgStuA}$ in $\mathrm{F}$. graminearum greatly reduced production of secondary metabolites. As previously mentioned, trichothecenes 15ADON $(<1 \%)$ and DON (not detected) are greatly reduced or absent in culture, and do not accumulate in wheat spikelets inoculated with the mutant. Loss of toxins is also strongly supported by gene expression data, especially in wheat, where the entire trichothecene cluster is not detected in $\Delta F g S t u A$, in contrast to high expression of these genes in the wild type. Additionally, the red pigment aurofusarin is reduced in the $\Delta F g S t u A$ mutant on both PDA and V8 agar. In all, 17 adjacent genes, including all known aurofusarin-related genes, were highly expressed in the wild type during sporulation (CMC) but were mostly absent or reduced in the $\triangle F g S t u A ~ m u-$ tant. There is an interesting connection between loss of pigment and loss of sporulation in the mutant. A similar connection between sporulation and secondary metabolism has been noted previously (Calvo et al. 2002); however, deletion of the polyketide synthase (PKS12) required for aurofusarin production in $F$. graminearum increased conidia production 10 -fold (Malz et al. 2005). Here, conidia production and the red pigment probably are only stimulated by the CMC medium. All three gene-expression experiments reported here support the idea that secondary metabolism, in general, is reduced in the $\Delta F g$ StuA mutant.

Catalase activity was reduced in the spores of the $\Delta F g$ StuA mutant, which showed a higher sensitivity to oxidative stress and had lower catalase activity than the wild type. Catalase gene expression also is reduced in the mycelia of the $\Delta F g S t u A$ mutant, and this might influence its ability to infect by reducing its ability to overcome oxidative stress defense responses by the plant. These results are consistent with reports from others that catalase activity could be regulated by StuAp. In $A$. fumigatus, the stuA mutant was reduced in expression of catalase gene CAT1 in hyphae, and the mutant was markedly more susceptible to oxidative stress (Sheppard et al. 2005). The putative CAT1 homolog in F. graminearum (FGSG_06733) was not found to be differentially expressed (data not shown). Also, the $A$. nidulans catalase gene $c p e A$ was shown to be reduced in expression in an stuA mutant (Scherer et al. 2002). Two homologous catalase genes in F. graminearum (FGSG_02974 and FGSG_12369; Fig. 7A) were actually increased in expression in the $\Delta F g$ StuA mutant during growth in culture but, during wheat infection, were greatly reduced in the mutant.

Hydrophobins are cell wall proteins required for the production of aerial hyphae or normal conidiophores in filamentous fungi, and help to overcome surface tension and to prevent desiccation to aerial hyphae (Fuchs et al. 2004). The hydrophobicity of the $\Delta F g S t u A$ mutant was clearly reduced because the surface of the mutant mycelia was more wettable than the wild type. It is currently unclear whether the reduced hydrophobicity reflects differences in the mycelium itself, due to lack of conidia borne on the mycelial surface, or is a result of the stunted aerial hyphae. Several predicted hydrophobinrelated genes showed lower expression in the $\Delta F g S t u A$ mutant, especially on sporulation medium. A $G$. cingulata StuA deletion mutant also showed a more wettable phenotype (Tong et al. 2007), and a StuA deletion mutant in A. fumigatus showed reduced expression of the conidial hydrophobin gene $\operatorname{rod} B$ (Sheppard et al. 2005). Reduced accumulation of hydrophobins also may contribute to attenuation of pathogenicity of the $\triangle F g S t u A$ mutant by reducing adherence to host tissue, as seen for mutants of the hydrophobin gene MPG1 in M. grisea (Talbot et al. 1996).

A link between nitrogen-limiting conditions and asexual sporulation has been previously observed, and this effect may be mediated by StuAp (Adams et al. 1998; Dahlberg and Vanetten 1982). The FgStuA gene showed constitutive expression in the wild-type strain under all conditions for which there are microarray data, including expression in planta, during germination of both ascospores and conidia, during peri- 
thecia development, on complete medium, and during $\mathrm{C}$ and $\mathrm{N}$ starvation. However, expression levels are especially high during $\mathrm{N}$ starvation. FgStuA also showed increased expression at 72 and $96 \mathrm{~h}$ in the wild-type strain in a wheat infection time course, time points which coincide with the appearance of disease symptoms and asexual sporulation on infected plants (Anderson 1948). There is also an overlapping set of genes more highly expressed during sporulation on CMC medium and during growth on $\mathrm{N}$ starvation medium (data not shown). In fact, $72 \%$ of the probesets with higher expression in wildtype $\mathrm{PH}-1$ during asexual spore production on CMC medium also have higher expression during $\mathrm{N}$ starvation.

StuAp appears to exert developmental control by way of negative regulation of genes involved in cell-cycle control. All known StuAp homologues regulate reversible transitions between a spherical cell types (e.g., a budding yeast cell, conidiophores, ascospores, and chlamydospores) and an elongated filamentous cells (e.g., true hyphae, pseudohyphae, and opaqueform cell) (Doedt et al. 2004). The APSES domain of StuAp in A. nidulans shares significant homology with DNA-binding domains of transcription factors controlling the critical G1/S phase cell-cycle transition in both $S$. cerevisiae and $S$. pombe (Dutton et al. 1997). In eukaryotic cells, genes required for DNA replication are periodically transcribed in the cell cycle, peaking at G1-S phase under control of specific transcription factors, such as the Mbp1/Swi6 complex in S. cerevisiae (Koch et al. 1993; Verma et al. 1992). The DNA-binding motif required for StuA response in Aspergillus spp. was also found enriched in the promoter sequences of genes belonging to the functional category "Cell cycle and DNA processing" in the three ascomycetes $F$. graminearum, $N$. crassa, and $S$. cerevisiae. Genes in the MIPS category "Cell cycle and DNA processing" were also found enriched among those genes more highly expressed in the $\Delta F g S t u A$ mutant compared with the wild type. Because expression was elevated for those genes in the mutant, FgStuAp appears to act as a repressor, similar to what has been found for A. nidulans (Doedt et al. 2004; Dutton et al. 1997).

The profound and pervasive impact of FgStuAp on the development of $F$. graminearum has been clearly documented in the $\Delta F g$ StuA strain. Under conditions conducive to sporulation or secondary metabolite synthesis or during plant infection, the mutant has a drastically altered phenotype. These phenotypes-reduced sporulation, altered spore morphology, reduced toxin accumulation, and so on-may be explained by modulation of gene expression for particular enzymes, structural elements, or biosynthetic pathways that will impact such development. Because FgStuA affects such a large number of genes and pathways, it makes it difficult to distinguish primary and secondary effects of this developmental regulator. Further work will be required to determine the primary set of genes directly regulated by FgStuAp.

\section{MATERIALS AND METHODS}

\section{Strains and culture conditions.}

The $F$. graminearum $\mathrm{PH}-1$ and the $\Delta F g$ StuA deletion mutant generated from PH-1 were used in this study. For characterization of vegetative growth and asexual development, the following media were used: V8 agar (20\% V8 juice, $0.2 \%$ $\mathrm{CaCO}_{3}$, and $1.5 \%$ Bacto-agar), PDA (Difco, BD, Franklin Lakes, NJ, U.S.A.), CM (Correll et al. 1987), CMC (Cappellini and Peterson 1965), liquid mung bean medium (Bai and Shaner 1996), and MM (Pontecorvo et al. 1953). Carrot agar (20\% carrots and $1.5 \%$ agar) was used for sexual development and crossings using $1 \mathrm{ml}$ of $2.5 \%$ Tween 60 per $20-\mathrm{ml}$ petri dish, as previously described (Pasquali and Kistler 2006). To examine colony surface hydrophobicity, a 30- $\mu$ droplet of $\mathrm{dH}_{2} \mathrm{O}$ was added to the top of 4-day-old fungal colonies grown on V8 agar and the persistence of the water droplet was examined over time.

\section{Fungal transformation and generation of the $\Delta \boldsymbol{F g S t u A}$ mutant.}

The DNA sequence was analyzed using the MIPS $F$. graminearum Genome DataBase (Guldener et al. 2006a). The split marker recombination procedure (Catlett et al. 2003), as described by Goswami and associates (2006), was used for gene replacement of FgStuA (FGSG_10129) in the F. graminearum PH-1 (NRRL 31084) (Fig. 1A). In total, 22 colonies were selected, 4 had the stunned phenotype common for stuA mutants in other fungi, and 2 of these were selected for Southern and DNA analysis (Fig. 1B and C). For DNA isolation, the strains were grown on CM and DNA was isolated according to a protocol described by Pasquali and associates (2004). PCR was performed, and the PCR products were purified with QIAquick PCR Purification kit (Qiagen, Valencia, CA, U.S.A.). Protoplast preparation and fungal transformation were performed as described previously (Hou et al. 2002). Transformants were cultivated on V8 juice agar with hygromycin B at $250 \mu \mathrm{g} / \mathrm{ml}$ (Calbiochem, La Jolla, CA, U.S.A.) and single-spore isolates were analyzed by Southern (Fig. 1B and C) and PCR (Fig. 1D). Southern hybridization was performed according to a protocol described by Goswami and associates (2006) using $5 \mu \mathrm{g}$ of DNA digested with PstI. The hph gene fragment amplified with primers $\mathrm{HY} 1 \mathrm{~F}$ and YG2R and a rightflanking probe amplified with primers $10129-3 \mathrm{~F}$ and 10129$4 \mathrm{R}$ were used to confirm gene deletion of FG10129 and single integration of the $h p h$ gene. In addition, PCR was also used for verification of mutants with primers 10129f/r (Fig. 1D) using a rapid microwave treatment of the fungal samples for DNA extraction (Tendulkar et al. 2003).

\section{Microarray experiments.}

Three microarray experiments were performed with the $\Delta F g$ StuA mutant to establish gene expression profiles during asexual (macroconidium) sporulation in CMC medium, during infection of wheat, and during induction of secondary metabolites on SecMet medium as described by Miller and MacKenzie (2000). For RNA extraction during sporulation, the cultures were grown in $100 \mathrm{ml}$ of liquid $\mathrm{CMC}$ media at $25^{\circ} \mathrm{C}$, with constant light (60 Lux) and $150 \mathrm{rpm}$ shaking for $24 \mathrm{~h}$. The cultures were filtered through Miracloth and the mycelia were washed 10 times with $50 \mathrm{ml}$ of $\mathrm{dH}_{2} \mathrm{O}$ to remove all spores. Total RNA was then extracted from the filtered sporulating mycelia. For RNA extraction during wheat (Triticum aestivum) infection, cv. Bobwhite was grown as previously described (Goswami and Kistler 2005). All spikelets were point inoculated at anthesis with $10 \mu \mathrm{l}$ of conidial suspension of $\mathrm{PH}-1$ or the $\Delta F g S t u A$ mutant in $0.01 \%$ Triton 60 solution $\left(10^{5}\right.$ spores $\left./ \mathrm{ml}\right)$. After inoculation, the plants were placed in a growth chamber at $16^{\circ} \mathrm{C}$ for 8 $\mathrm{h}$ (night) and $18^{\circ} \mathrm{C}$ for $16 \mathrm{~h}$ (day), and the heads were covered with plastic bags to increase the humidity. The plastic bags were removed after $48 \mathrm{~h}$ and the heads were collected after an additional $24 \mathrm{~h}$ of growth (total $72 \mathrm{~h}$ ), and immediately frozen at $-80^{\circ} \mathrm{C}$ prior to RNA extraction. Four heads were pooled per biological replicate. For RNA extraction during SecMet production, the wild type or $\Delta F g S t u A$ mutant were cultivated in two consecutive media by a previously described method (Miller and MacKenzie 2000). Total RNA was extracted from the fungal tissue after 3 days of growth on the second medium. The same fungal tissue also was used to analyze trichothecene production (see below: "Mycotoxin and ergosterol analysis"). All the experiments were replicated three times. 
Total RNA was isolated using TRIzol reagent (Invitrogen, Carlsbad, CA, U.S.A.) and purified with an RNeasy Mini kit (Qiagen) according to the manufacturers' instructions. Total RNA $(10 \mu \mathrm{g})$ was labeled according to Affymetrix eukaryotic RNA-labeling protocols (Affymetrix, Santa Clara, CA, U.S.A.). The labeled RNA was hybridized with $F$. graminearum Affymetrix GeneChip (Guldener et al. 2006b), using three biological replications for each experiment. The processing and data acquisition from chips followed standard Affymetrix procedures in use at the Biomedical Image Processing Facility at the University of Minnesota. The resulting CEL files were analyzed with Genedata Expressionist software. The CEL files were normalized using a robust multichip analysis algorithm and all experiments were performed at $P=0.04$. A $t$ test was used to analyze differential expression, and only probe sets expressed at greater than or equal to twofold were considered. A present-or-absent test was also performed, where "present" indicated significant signal from the probe sets above background in at least two of the three biological replicate chips and "absent" indicated signal not significantly above background in at least two out of three chips. Genes showing differential expression patterns based on either the $t$ test or the present-or-absent test (the unique probe sets) are considered as differentially expressed genes. MIPS FunCat was used to analyze functional categories from differentially expressed genes (Ruepp et al. 2004). PCA was performed with correlations of items (probesets) using covariance matrix and 50\% valid values in Genedata Expressionist software. Data from the microarray experiments are stored as experiment FG13 at PLEXdb (Wise et al. 2006).

\section{Mycotoxin and ergosterol analysis.}

Determinations of trichothecene accumulation were performed after growth on SecMet media and after wheat inoculations, using cv. Bobwhite. For the SecMet experiments, the fungal cultures were grown as described above, the mycelium suspension was filtered, and $20 \mathrm{ml}$ of the liquid phase were mixed with ethyl acetate on a shaker at $150 \mathrm{rpm}$ for $2 \mathrm{~h}$ prior to analysis. For determination of trichothecene production on inoculated wheat heads, the $\mathrm{PH}-1$ or $\Delta F g S t u A$ mutant were point inoculated on a single spikelet at anthesis, using $10 \mu \mathrm{l}$ of conidial suspension $\left(10^{6}\right.$ spores $\left./ \mathrm{ml}\right)$ in $0.01 \%$ Triton 60 solution. After inoculation, wheat plants were placed in a humidity chamber for $48 \mathrm{~h}$, then kept in a greenhouse at $20^{\circ} \mathrm{C}$ for an additional 12 days (total $=14$ days). The single inoculated spikelet was analyzed for trichothecenes and was replicated on 10 heads. To determine DON and 15ADON concentration both on SecMet and in wheat, the samples were processed by gas chromatography, mass spectrometry analysis following the method described by Mirocha and associates (1998). Ergosterol content was measured on the lyophilized filtered mycelia obtained after the SecMet growth, according to the protocol described by Dong and associates (2006).

\section{Pathogenicity test.}

The pathogenicity of $\mathrm{PH}-1$ and the $\Delta F g S t u A$ mutant on wheat (cv. Norm) was evaluated as previously described (Goswami and Kistler 2005). One spikelet was either point inoculated at anthesis with $10 \mu \mathrm{l}$ of conidial suspension $\left(10^{3}\right.$ spores/ $\mu \mathrm{l}$ ) or with a $2-\mathrm{mm}^{2}$ mycelial mat of $\mathrm{PH}-1$ or the $\triangle F g S t u A$ mutant in $0.01 \%$ Triton 60 solution. Mock inoculations were conducted in a similar manner with the Triton 60 solution alone. After inoculation, wheat plants were placed in a humidity chamber for $48 \mathrm{~h}$, then kept in a greenhouse at $20^{\circ} \mathrm{C}$ for an additional 12 days (total $=14$ days). Thirty plants were inoculated and the experiment was repeated three times. The pathogenicity was scored by counting the number of spikelets showing disease symptoms (necrosis or bleaching of palea or lemma) as previously described (Goswami and Kistler 2005). In total, 10 spikelets on each wheat head were evaluated for the presence of disease symptoms by scoring 5 spikelets above and 4 spikelets below the point of inoculation. $\triangle F g S t u A$-inoculated spikelets were plated on V8 to verify viability of the mutant inside the plant tissue.

To examine the ability to colonize apple, 2-mm V8 agar plugs of PH-1 and $\triangle F g S t u A$ were inoculated on $1-\mathrm{cm}$ apple discs and 2-by-1-by-2-cm pieces of cv. Gala. The spread of the fungus was measured in diameter and the color and softness of the lesion were evaluated to identify degrading activity by the fungus.

\section{Catalase spectrophotometer assay.}

To analyze catalase activity in macroconidia, spores $(1 \times$ $10^{5} / \mathrm{ml}$ ) of PH-1 or $\Delta F g S t u A$ were suspended in $5 \mathrm{mM} \mathrm{H}_{2} \mathrm{O}_{2}$. The extinction coefficient of $\mathrm{H}_{2} \mathrm{O}_{2}$ at $240 \mathrm{~nm}$ is $43.6 \mathrm{M}^{-1} \mathrm{~cm}^{-1}$ (Noble and Gibson 1970). The absorbance at $240 \mathrm{~nm}$ was measured every minute for $2 \mathrm{~h}$ using a Beckman DU 640 spectrophotometer (Beckman Coulter, Fullerton, CA, U.S.A.).

\section{Promoter analysis.}

To investigate enrichment of a specific motif in the promoter regions for selected genes in $F$. graminearum and $N$. crassa, 1 kb upstream of each gene ("genes_upstream_1000") was obtained from the Broad Institute database. For pattern matching, the RSAT program (van Helden 2003), available online, was used with the tool "dna-pattern". For promoter analysis of $S$. cerevisiae, we used the tool "genome-scale dna-pattern" (using only 500 nucleotides upstream included in the software). The background frequency of a motif was calculated on the basis of the 1-kb (or 500-bp for $S$. cerevisiae) nucleotide upstream sequences for all predicted genes in the genome. Enrichment of a motif in the promoter sequences of selected genes, compared with the background frequency, was calculated using a $\chi^{2}$ test using the software "R".

\section{ACKNOWLEDGMENTS}

We thank W. Xu and the University of Minnesota, Supercomputing Institute for advice and computing resources that made this study possible; K.-Y. Seong for technical suggestions; K. Hilburn (United States Department of Agriculture [USDA]-Agricultural Research Service Cereal Disease Laboratory) for outstanding technical assistance; S. S. Klemsdal (Bioforsk) for support; H. Divon (Bioforsk) for a critical read through; U. Güldener (Institute of Bioinformatics and Systems Biology, German Research Center for Environmental Health) for assistance with MIPS FunCat analysis; and A. di Pietro (University of Cordoba) for providing the apple infection protocol. This project was supported by the National Research Initiative of the USDA Cooperative State Research, Education and Extension Service, grant 2004-35604-14327, and the BILAT project 173277 supported by the Research Council of Norway. M. Pasquali was financially supported by the "Branco Weiss-Society in Science" Fellowship.

\section{LITERATURE CITED}

Adams, T. H., Wieser, J. K., and Yu, J. H. 1998. Asexual sporulation in Aspergillus nidulans. Microbiol. Mol. Biol. Rev. 62:35-54.

Anderson, A. L. 1948. The development of Gibberella zeae head blight of wheat. Phytopathology 38:595-611.

Aramayo, R., Peleg, Y., Addison, R., and Metzenberg, R. 1996. Asm-1 ${ }^{+}$, a Neurospora crassa gene related to transcriptional regulators of fungal development. Genetics 144:991-1003.

Bai, G. H., and Shaner, G. 1996. Variation in Fusarium graminearum and cultivar resistance to wheat scab. Plant Dis. 80:975-979.

Borneman, A. R., Hynes, M. J., and Andrianopoulos, A. 2002. A basic helix-loop-helix protein with similarity to the fungal morphological regulators, Phd1p, Efg1p and StuA, controls conidiation but not dimorphic growth in Penicillium marneffei. Mol. Microbiol. 44:621-631.

Calvo, A. M., Wilson, R. A., Bok, J. W., and Keller, N. P. 2002. Relation- 
ship between secondary metabolism and fungal development. Microbiol. Mol. Biol. Rev. 66:447-459.

Cappellini, R. A., and Peterson, J. L. 1965. Macroconidium formation in submerged cultures by a non-sporulating strain of Gibberella zeae. Mycologia 57:962-966.

Catlett, N. L., Lee, B. N., Yoder, O. C., and Turgeon, B. G. 2003. Splitmarker recombination for efficient targeted deletion of fungal genes. Fungal Genet. Newsl. 50:9-11.

Clutterbuck, A. J. 1969. A mutational analysis of conidial development in Aspergillus nidulans. Genetics 63:317-327.

Correll, J. C., Klittich, C. J. R., and Leslie, J. F. 1987. Nitrate non-utilizing mutants of Fusarium oxysporum and their use in vegetative compatibility tests. Phytopathology 77:1640-1646.

Cuomo, C. A., Gueldener, U., Xu, J. R., Trail, F., Turgeon, B. G., Di Pietro, A., Walton, J. D., Ma, L. J., Baker, S. E., Rep, M., Adam, G., Antoniw, J., Baldwin, T., Calvo, S., Chang, Y. L., DeCaprio, D., Gale, L. R., Gnerre, S., Goswami, R. S., Hammond-Kosack, K., Harris, L. J., Hilburn, K., Kennell, J. C., Kroken, S., Magnuson, J. K., Mannhaupt, G., Mauceli, E., Mewes, H. W., Mitterbauer, R., Muehlbauer, G., Munsterkotter, M., Nelson, D., O’Donnell, K., Ouellet, T., Qi, W. H., Quesneville, H., Roncero, M. I. G., Seong, K. Y., Tetko, I. V., Urban, M., Waalwijk, C., Ward, T. J., Yao, J. Q., Birren, B. W., and Kistler, H. C. 2007. The Fusarium graminearum genome reveals a link between localized polymorphism and pathogen specialization. Science 317:1400-1402.

Dahlberg, K. R., and Vanetten, J. L. 1982. Physiology and biochemistry of fungal sporulation. Annu. Rev. Phytopathol. 20:281-301.

Doedt, T., Krishnamurthy, S., Bockmuhl, D. P., Tebarth, B., Stempel, C., Russell, C. L., Brown, A. J. P., and Ernst, J. F. 2004. APSES proteins regulate morphogenesis and metabolism in Candida albicans. Mol. Biol. Cell 15:3167-3180.

Dong, Y. H., Steffenson, B. J., and Mirocha, C. J. 2006. Analysis of ergosterol in single kernel and ground grain by gas chromatography-mass spectrometry. J. Agric. Food Chem. 54:4121-4125.

Dutton, J. R., Johns, S., and Miller, B. L. 1997. StuAp is a sequence-specific transcription factor that regulates developmental complexity in Aspergillus nidulans. EMBO (Eur. Mol. Biol. Organ.) J. 16:5710-5721.

Frandsen, R. J. N., Nielsen, N. J., Maolanon, N., Sorensen, J. C., Olsson, S., Nielsen, J., and Giese, H. 2006. The biosynthetic pathway for aurofusarin in Fusarium graminearum reveals a close link between the naphthoquinones and naphthopyrones. Mol. Microbiol. 61:1069-1080.

Fuchs, U., Czymmek, K. J., and Sweigard, J. A. 2004. Five hydrophobin genes in Fusarium verticillioides include two required for microconidial chain formation. Fungal Genet. Biol. 41:852-864.

Gimeno, C. J., and Fink, G. R. 1994. Induction of pseudohyphal growth by overexpression of Phdl, a Saccharomyces cerevisiae gene related to transcriptional regulators of fungal development. Mol. Cell. Biol. 14:2100-2112.

Goswami, R. S., and Kistler, H. C. 2004. Heading for disaster: Fusarium graminearum on cereal crops. Mol. Plant Pathol. 5:515-525.

Goswami, R. S., and Kistler, H. C. 2005. Pathogenicity and in planta mycotoxin accumulation among members of the Fusarium graminearum species complex on wheat and rice. Phytopathology 95:1397-1404.

Goswami, R. S., Xu, J. R., Trail, F., Hilburn, K., and Kistler, H. C. 2006. Genomic analysis of host-pathogen interaction between Fusarium graminearum and wheat during early stages of disease development. Microbiology 152:1877-1890.

Gravelat, F. N., Doedt, T., Chiang, L. Y., Liu, H., Filler, S. G., Patterson, T. F., and Sheppard, D. C. 2008. In vivo analysis of Aspergillus fumigatus developmental gene expression determined by real-time reverse transcription-PCR. Infect. Immun. 76:3632-3639.

Guldener, U., Mannhaupt, G., Munsterkotter, M., Haase, D., Oesterheld, M., Stumpflen, V., Mewes, H. W., and Adam, G. 2006a. FGDB: A comprehensive fungal genome resource on the plant pathogen Fusarium graminearum. Nucleic Acids Res. 34:456-458.

Guldener, U., Seong, K. Y., Boddu, J., Cho, S., Trail, F., Xu, J. R., Adam, G., Mewes, H. W., Muehlbauer, G. J., and Kistler, H. C. 2006b. Development of a Fusarium graminearum Affymetrix GeneChip for profiling fungal gene expression in vitro and in planta. Fungal Genet. Biol. 43:316-325.

Hou, Z. M., Xue, C. Y., Peng, Y. L., Katan, T., Kistler, H. C., and Xu, J. R. 2002. A mitogen-activated protein kinase gene (MGV1) in Fusarium graminearum is required for female fertility, heterokaryon formation, and plant infection. Mol. Plant-Microbe Interact. 15:1119-1127.

Iyer, L. M., Koonin, E. V., and Aravind, L. 2002. Extensive domain shuffling in transcription regulators of DNA viruses and implications for the origin of fungal APSES transcription factors. Genome Biol. 3(3).

Jansen, C., von Wettstein, D., Schafer, W., Kogel, K. H., Felk, A., and Maier, F. J. 2005. Infection patterns in barley and wheat spikes inoculated with wild-type and trichodiene synthase gene disrupted Fusarium graminearum. Proc. Natl. Acad. Sci. U.S.A. 102:16892-16897.
Koch, C., Moll, T., Neuberg, M., Ahorn, H., and Nasmyth, K. 1993. A role for the transcription factors Mbp1 and Swi4 in progression from G1 to S phase. Science 261:1551-1557.

Korting, H. C., Hube, B., Oberbauer, S., Januschke, E., Hamm, G. Albrecht, A., Borelli, C., and Schaller, M. 2003. Reduced expression of the hyphal-independent Candida albicans proteinase genes SAP1 and SAP3 in the efg1 mutant is associated with attenuated virulence during infection of oral epithelium. J. Med. Microbiol. 52:623-632.

Lee, T. I., Rinaldi, N. J., Robert, F., Odom, D. T., Bar-Joseph, Z., Gerber, G. K., Hannett, N. M., Harbison, C. T., Thompson, C. M., Simon, I., Zeitlinger, J., Jennings, E. G., Murray, H. L., Gordon, D. B., Ren, B., Wyrick, J. J., Tagne, J. B., Volkert, T. L., Fraenkel, E., Gifford, D. K., and Young, R. A. 2002. Transcriptional regulatory networks in Saccharomyces cerevisiae. Science 298:799-804.

Lengeler, K. B., Davidson, R. C., D'Souza, C., Harashima, T., Shen, W. C., Wang, P., Pan, X. W., Waugh, M., and Heitman, J. 2000. Signal transduction cascades regulating fungal development and virulence. Microbiol. Mol. Biol. Rev. 64:746-785.

Lo, H. J., Kohler, J. R., DiDomenico, B., Loebenberg, D., Cacciapuoti, A., and Fink, G. R. 1997. Nonfilamentous C. albicans mutants are avirulent. Cell 90:939-949.

Malz, S., Grell, M. N., Thrane, C., Maier, F. J., Rosager, P., Felk, A., Albertsen, K. S., Salomon, S., Bohn, L., Schäfer, W., and Giese, H. 2005. Identification of a gene cluster responsible for the biosynthesis of aurofusarin in the Fusarium graminearum species complex. Fungal Genet. Biol. 42:420-433.

McMullen, M., Jones, R., and Gallenberg, D. 1997. Scab of wheat and barley: A re-emerging disease of devastating impact. Plant Dis. 81:1340-1348

Miller, J. D., and MacKenzie, S. 2000. Secondary metabolites of Fusarium venenatum strains with deletions in the Tri5 gene encoding trichodiene synthetase. Mycologia 92:764-771.

Miller, K. Y., Wu, J. G., and Miller, B. L. 1992. Stua is required for cell pattern formation in Aspergillus. Genes Dev. 6:1770-1782.

Mirocha, C. J., Kolaczkowski, E., Xie, W. P., Yu, H., and Jelen, H. 1998 Analysis of deoxynivalenol and its derivatives (batch and single kernel) using gas chromatography mass spectrometry. J. Agric. Food Chem. 46:1414-1418.

Noble, R. W., and Gibson, Q. H. 1970. The reaction of ferrous horseradish peroxidase with hydrogen peroxide. J. Biol. Chem. 245:2409-2413.

Ohara, T., and Tsuge, T. 2004. FoSTUA, encoding a basic helix-loop-helix protein, differentially regulates development of three kinds of asexual spores, macroconidia, microconidia, and chlamydospores, in the fungal plant pathogen Fusarium oxysporum. Eukaryot. Cell 3:1412-1422.

Olivain, C., and Alabouvette, C. 1999. Process of tomato root colonization by a pathogenic strain of Fusarium oxysporum f. sp. lycopersici in comparison with a non-pathogenic strain. New Phytol. 141:497-510.

Pasquali, M., and Kistler, H. C. 2006. Gibberella zeae ascospore production and collection for microarray experiments. J. Vis. Exp. Published online. doi: 10.3791/115.

Pasquali, M., Marena, L., Fiora, E., Piatti, P., Gullino, M. L., and Garibaldi, A. 2004. Real-time polymerase chain reaction for identification of a highly pathogenic group of Fusarium oxysporum f. sp. chrysanthemi on argyranthemum frutescens $L$. J. Plant Pathol. 86:53-59.

Pontecorvo, G., Roper, A. B., Hemmons, L. M., MacDonald, K. D., and Bufton, A. W. 1953. The genetics of Aspergillus nidulans. Adv. Genet. 5:141-238.

Ramirez-Zavala, B., and Dominguez, A. 2008. Evolution and phylogenetic relationships of APSES proteins from Hemiascomycetes. FEMS (Fed. Eur. Microbiol. Soc.) Yeast Res. 8:511-519.

Ruepp, A., Zollner, A., Maier, D., Albermann, K., Hani, J., Mokrejs, M., Tetko, I., Guldener, U., Mannhaupt, G., Munsterkotter, M., and Mewes, H. W. 2004. The FunCat, a functional annotation scheme for systematic classification of proteins from whole genomes. Nucleic Acids Res. 32:5539-5545

Scherer, M., Wei, H. J., Liese, R., and Fischer, R. 2002. Aspergillus nidulans catalase-peroxidase gene (cpeA) is transcriptionally induced during sexual development through the transcription factor StuA. Eukaryot. Cell 1:725-735.

Schmit, J. C., and Brody, S. 1976. Biochemical genetics of Neurospora crassa conidial germination. Bacteriol. Rev. 40:1-41.

Seong, K. Y., Zhao, X., Xu, J. R., Guldener, U., and Kistler, H. C. 2008 Conidial germination in the filamentous fungus Fusarium graminearum. Fungal Genet. Biol. 45:389-399.

Sheppard, D. C., Doedt, T., Chiang, L. Y., Kim, H. S., Chen, D., Nierman, W. C., and Filler, S. G. 2005. The Aspergillus fumigatus StuA protein governs the up-regulation of a discrete transcriptional program during the acquisition of developmental competence. Mol. Biol. Cell 16:58665879

Sohn, K., Urban, C., Brunner, H., and Rupp, S. 2003. EFG1 is a major 
regulator of cell wall dynamics in Candida albicans as revealed by DNA microarrays. Mol. Microbiol. 47:89-102.

Staib, P., Kretschmar, M., Nichterlein, T., Hof, H., and Morschhauser, J. 2002. Transcriptional regulators Cph $1 \mathrm{p}$ and Efg1p mediate activation of the Candida albicans virulence gene SAP5 during infection. Infect. Immun. 70:921-927.

Stoldt, V. R., Sonneborn, A., Leuker, C. E., and Ernst, J. F. 1997. Efg1p, an essential regulator of morphogenesis of the human pathogen Candida albicans, is a member of a conserved class of bHLH proteins regulating morphogenetic processes in fungi. EMBO (Eur. Mol. Biol. Organ.) J. 16:1982-1991.

Talbot, N. J., Kershaw, M. J., Wakley, G. E., de Vries, O. M. H., Wessels, J. G. H., and Hamer, J. E. 1996. MPG1 encodes a fungal hydrophobin involved in surface interactions during infection-related development of Magnaporthe grisea. Plant Cell 8:985-999.

Tendulkar, S. R., Gupta, A., and Chattoo, B. B. 2003. A simple protocol for isolation of fungal DNA. Biotechnol. Lett. 25:1941-1944.

Tong, X. Z., Zhang, X. W., Plummer, K. M., Stowell, K. M., Sullivan, P. A., and Farley, P. C. 2007. GcSTUA, an APSES transcription factor, is required for generation of appressorial turgor pressure and full pathogenicity of Glomerella cingulata. Mol. Plant-Microbe Interact. 20:1102-1111.

Twumasi-Boateng, K., Yu, Y., Chen, D., Gravelat, F. N., Nierman, W. C., and Sheppard, D. C. 2009. Transcriptional profiling identifies a role for $\mathrm{BrlA}$ in the response to nitrogen depletion and for StuA in the regula- tion of secondary metabolite clusters in Aspergillus fumigatus. Eukaryot. Cell 8:104-115.

van Helden, J. 2003. Regulatory sequence analysis tools. Nucleic Acids Res. 31:3593-3596.

Verma, R., Smiley, J., Andrews, B., and Campbell, J. L. 1992. Regulation of the yeast DNA replication genes through the MluI cell cycle box is dependent on Swi6. Proc. Natl. Acad. Sci. U.S.A. 89:9479-9483.

Ward, M. P., Gimeno, C. J., Fink, G. R., and Garrett, S. 1995. Sok2 may regulate cyclic Amp-dependent protein kinase-stimulated growth and pseudohyphal development by repressing transcription. Mol. Cell. Biol. 15:6854-6863.

Wise, R., Caldo, R., Hong, L., Wu, S., Cannon, E., and Dickerson, J. 2006. PLEXdb: A unified expression profiling database for plants and plant pathogens. (Abstr.) Phytopathology 96:S161.

\section{AUTHOR-RECOMMENDED INTERNET RESOURCES}

The MIPS Fusarium graminearum genome database: mips.gsf.de/genre/proj/FGDB

Genedata website: www.genedata.com

Plant Expression database (PLEXdb): www.plexdb.org

Broad Institute website: www.broad.mit.edu

Regulatory Sequence Analysis Tools (RSAT) website: rsat.ulb.ac.be/rsat

The R Project for Statistical Computing website: www.r-project.org 